\title{
TERRESTRIAL VERTEBRATE BIOLOGICAL DIVERSITY IN TWELVE ANDES-AMAZON CONSERVATION MOSAICS
}

October 2020

GORDON AND BETTY

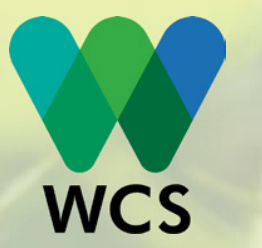





\section{TERRESTRIAL VERTEBRATE BIOLOGICAL DIVERSITY IN TWELVE ANDES-AMAZON CONSERVATION MOSAICS}

October

2020

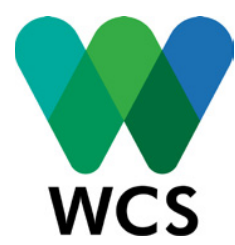




\section{TITLE: TERRESTRIAL VERTEBRATE BIOLOGICAL DIVERSITY IN TWELVE ANDES-AMAZON CONSERVATION MOSAICS}

First Edition: October 2020

Wildlife Conservation Society (WCS)

Authors: Robert Wallace, Omar Torrico, Zulia Porcel \& Enrique Domic

Editor: Robert Wallace

Technical writing:

PhD. Robert Wallace -Director of the Greater Madidi-Tambopata Landscape Conservation Program, WCS Bolivia

MSc. Omar Torrico - Head of Biodiversity Monitoring, WCS Bolivia

MSc. Zulia Porcel - Responsible for Biodiversity Monitoring, WCS Bolivia

Lic. Enrique Domic - Responsible for Biodiversity Monitoring, WCS Bolivia

Cover Photograph: Rob Wallace/WCS

Design: Omar Torrico

Photograph credits by page:

Robert Wallace/WCS: 2,6, 16, 22, 30 .

OmarTorrico/WCS: 1, 4, 8, 10, 11, 13, 15, 20, 26, 34.

For the production of these analyses we are especially grateful for the kind provision of species distribution data from the International Union for the Conservation of Nature (IUCN) Red List Data (Version 2019-1) for amphibians and mammals, BirdLife International for birds, and the Tel Aviv University (Department of Geography) for use of global reptile distributions. We would also like to acknowledge AmphibiaWeb, Reptile Database and the South American Classification Committee for additional information on amphibians, reptiles and birds, respectively.

Suggested citation: Wallace, R., Torrico, 0., Porcel, Z. \& Domic E. 2020. Terrestrial Vertebrate Biodiversity in Twelve AndesAmazon Conservation Units. Wildlife Conservation Society (WCS). La Paz, Bolivia.

ISBN: 978-99974-926-2-3

Printed in Bolivia 


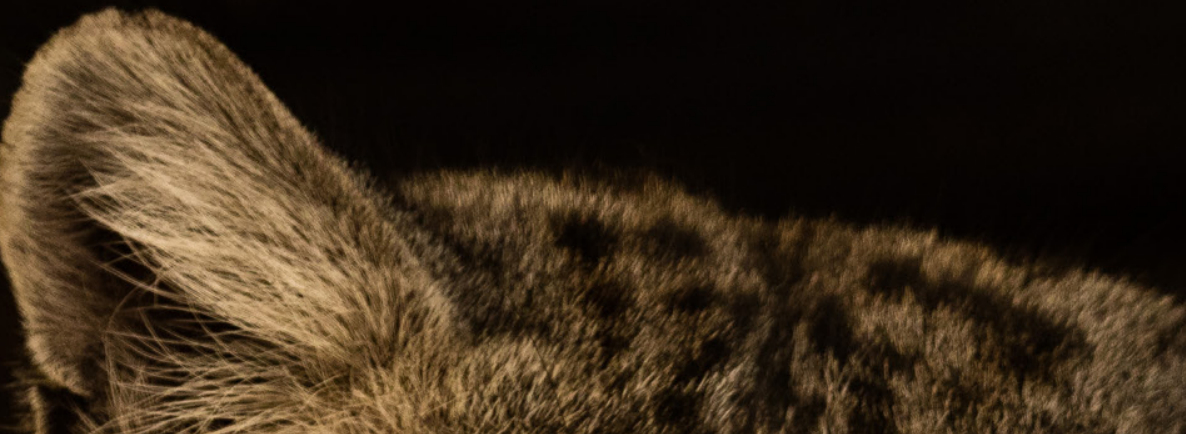

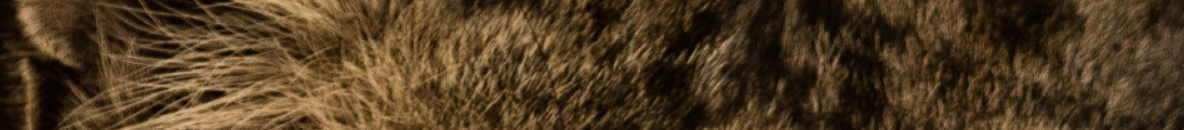

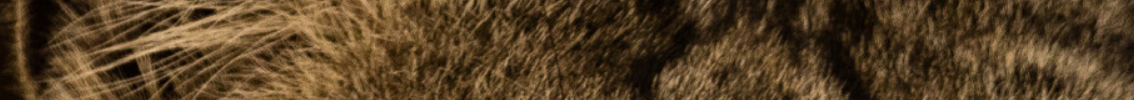

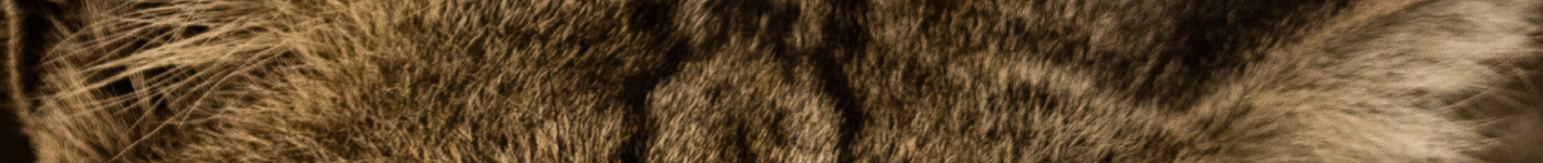
¿.J.
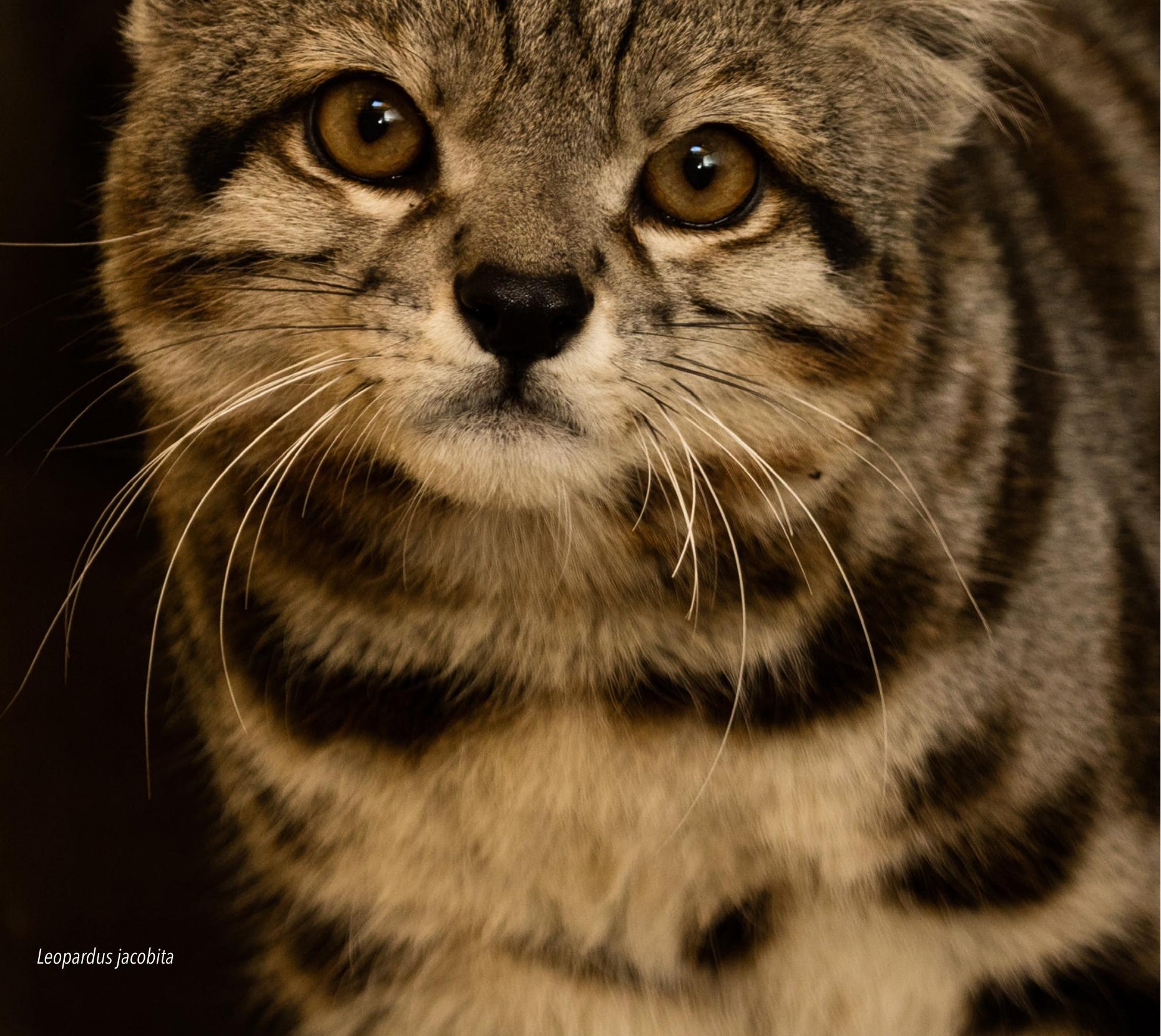


\section{Contents}

ABSTRACT

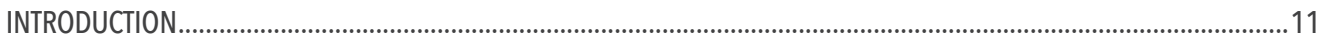

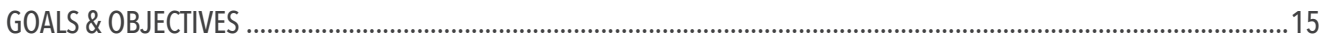

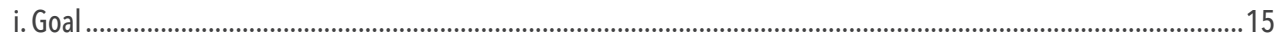

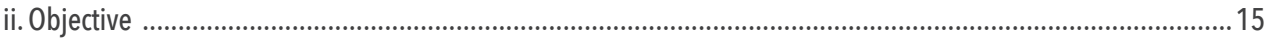

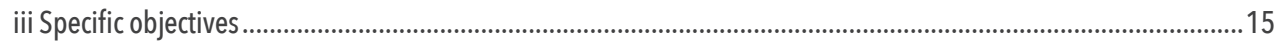

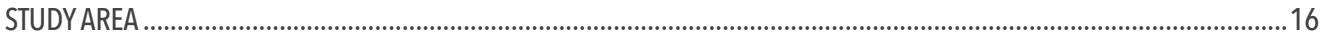

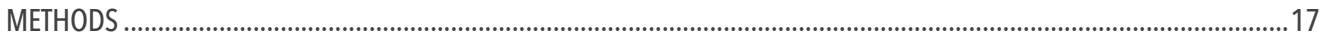

i. Taxonomic revision and update for amphibians, reptiles, birds and mammals....................................................18

ii. Creation of distribution polygons for amphibian, reptile and mammal species not evaluated by the IUCN .........19

iii. Identification of expected species in the twelve conservation mosaics supported by the Gordon and

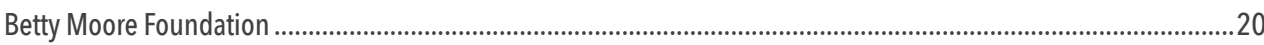

iv. Identification of confirmed species in the twelve conservation mosaics supported by the Gordon and

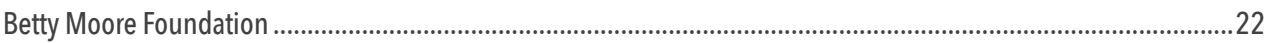

v. Contribution of the conservation mosaics supported by the Gordon and Betty Moore Foundation

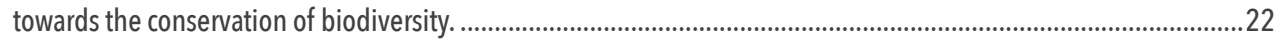

vi. Alpha-diversity analysis for the twelve conservation mosaics supported by the Gordon and Betty

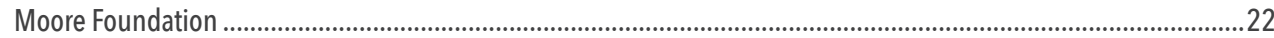

RESULTS 
i. Number of expected and confirmed species for four vertebrate groups in the twelve conservation

mosaics supported by Gordon and Betty Moore Foundation ...........................................................................2

ii. Representativeness of biological diversity of the twelve conservation mosaics supported by the Gordon

and Betty Moore Foundation

iii. Contribution of the twelve conservation mosaics supported by the Gordon and Betty Moore Foundation

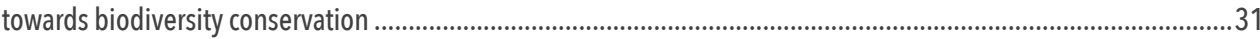

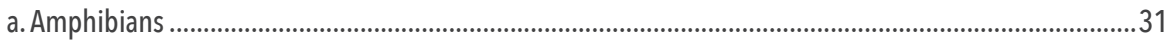

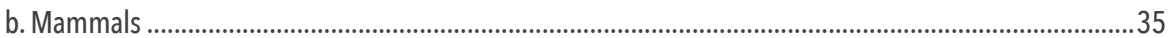

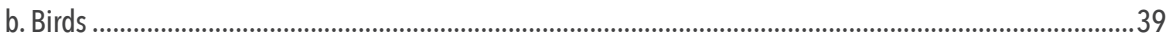

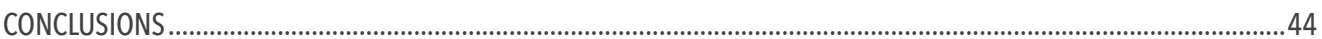

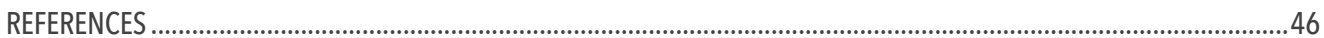

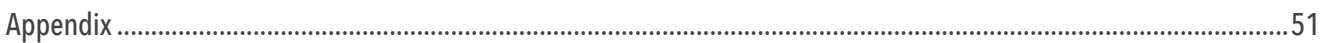


(3)

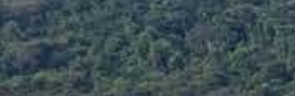

\section{$x^{2}+x^{2}$}

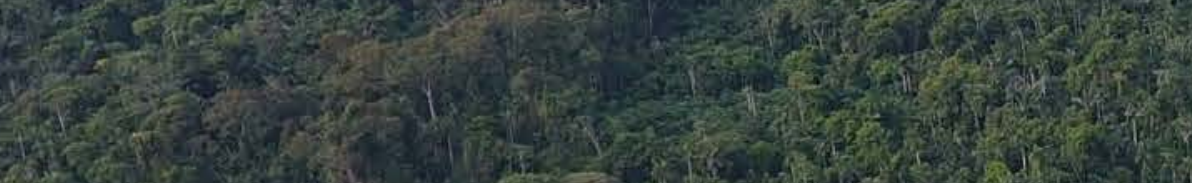

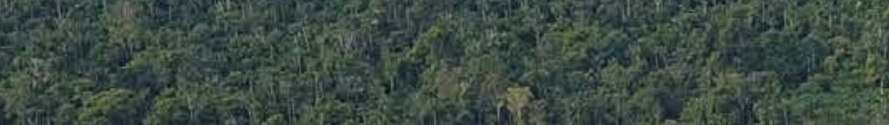

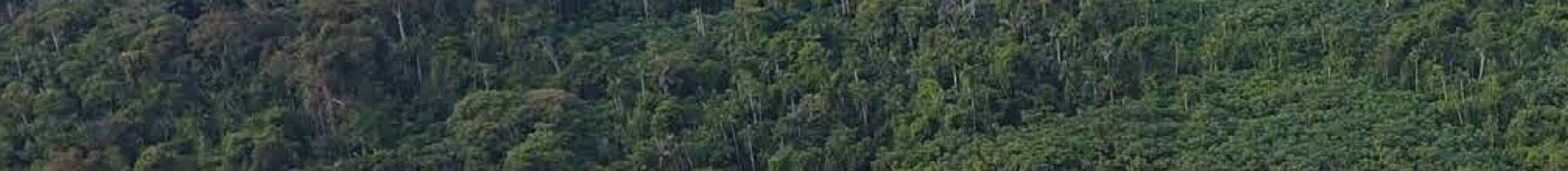
a (s)

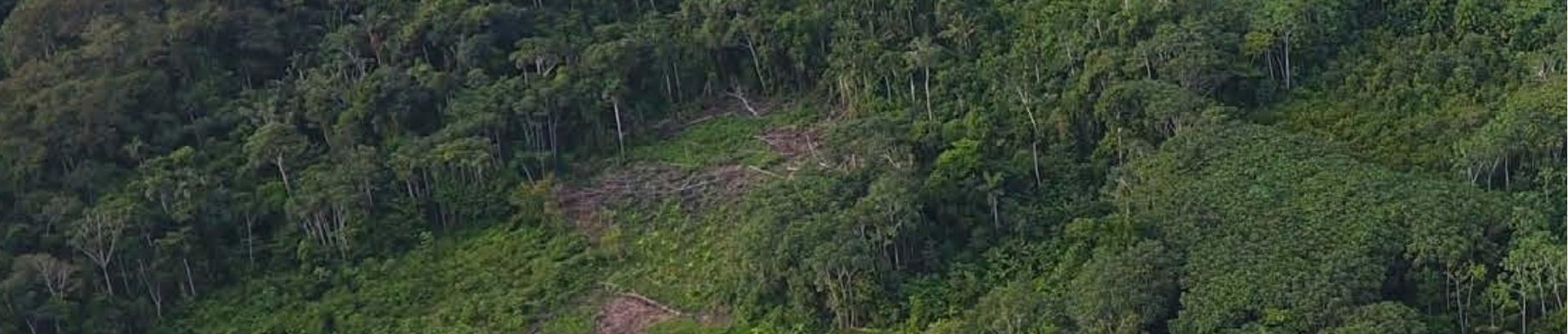

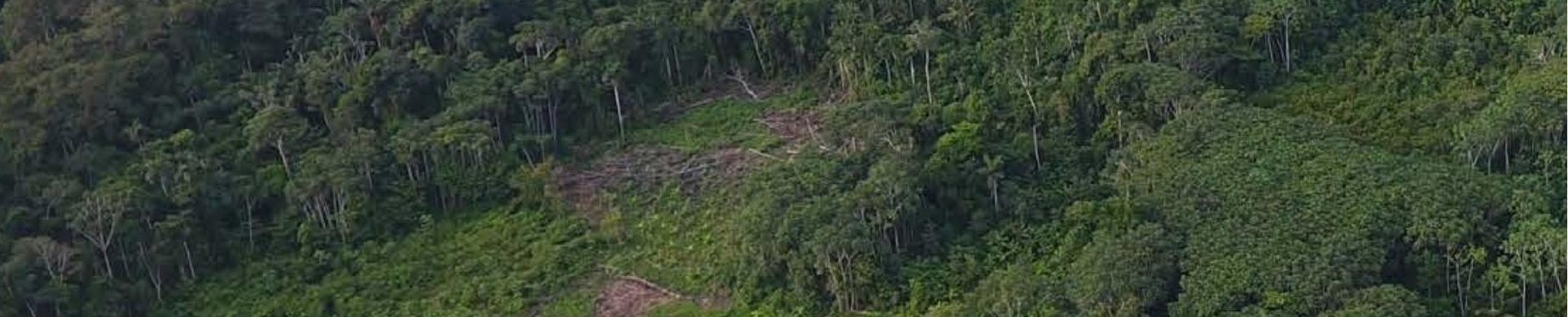




\section{ABSTRACT}

The Amazon basin is the largest tropical forest and greatest freshwater system in the world with extraordinary biodiversity and endemism across different taxonomic groups. Focusing on four vertebrate groups, amphibians, reptiles, birds and mammals, we demonstrate the incredible biodiversity value of the Amazon basin and the considerable conservation contribution of the twelve conservation mosaics supported by the Gordon and Betty Moore Foundation. The Gordon and Betty Moore Foundation defines a conservation mosaic as a large landscape composed of protected areas, indigenous territories, and other land use types. This concept is based on an integrated landscape approach adopted by many conservation organizations. Using geospatial information on species distribution from the IUCN for amphibians and mammals, Roll et al. (2017) for reptiles, and Bird Life International for birds, in this report we estimate the number of expected and confirmed species in the Amazon basin and the conservation mosaics. Across the four vertebrate groups the Amazon basin harbors 5,756 species, representing $56.92 \%$ of all South American species ( 10,108 species) for these groups. Similarly, the twelve conservation mosaics cover $53.84 \%$ of the Amazon basin and are expected to hold 3,836 species, representing $66.64 \%$ of Amazon species, $37.95 \%$ of South American species and $10.51 \%$ of species in the world.

Comparing the number of expected species in each of the twelve mosaics with the number of confirmed species to date, the 3,099 confirmed species represent $80.79 \%$ of the 3,836 expected species. Individually, the twelve mosaics are expected to harbor between 1,284 and 2,034 species (with between 430 and 1,708 species confirmed), highlighting the conservation mosaics of the western Amazon as those with the highest species concentrations, especially MadidiTambopata with 2,034 expected species (1,708 confirmed), Upper Purus with 1,972 expected species (1,747 confirmed), and Yasuni-Pastaza with 1,805 expected species (1,470 confirmed). Contrastingly, the Ampiyacu mosaic has the lowest number of expected species (1,284 species, with 430 confirmed species).

The Madidi-Tambopata conservation mosaic harbors the greatest number of expected species of birds (1,240 expected species and 1,197 confirmed) and mammals (335 expected species and 264 confirmed) of the twelve mosaics. YasuniPastaza is one of the smallest conservation mosaics, yet protects around $30 \%$ of all amphibians, reptiles, birds, and mammals in the Amazon. Indeed, all of the conservation mosaics supported by the Gordon and Betty Moore Foundation make vital biodiversity conservation contributions, with the twelve mosaics expected to protect $42.89 \%$ of amphibian species in the Amazon, $56.8 \%$ of reptiles, $80.02 \%$ of birds, and $76.66 \%$ of mammals.

To determine areas with high species concentrations and assess the representativeness of the conservation mosaics, we analyzed alpha-diversity of amphibians, birds and mammals in South America using the finest resolution to date $\left(1 \mathrm{~km}^{2}\right)$. The maximum values in South America for the three vertebrate groups were 136 amphibian species per km², 596 bird species per $\mathrm{km}^{2}$, and 216 mammal species per $\mathrm{km}^{2}$, and are found in the Amazon basin, especially the western Amazon, and notably within the Yasuni-Pastaza, Yavari-Samiria,Ampiyacu, Upper Purus, Madidi-Tambopata and Madeira conservation mosaics.

The concentrations in the Amazon of the most threatened species according to the IUCN (Critically Endangered, Endangered and Vulnerable) are found in the Chiribiquete-Caqueta, Itenez-Rondonia, Madeira, Xingu, Calha Norte and Yavari-Samiria conservation mosaics. Concentrations of amphibians in the same categories are found in Yasuni-Pastaza, Upper Purus, Yavari-Samiria, Ampiyacu, Lower Rio Negro, Calha Norte, Chiribiquete-Chaqueta, Upper Rio Negro, MadidiTambopata and Xingu conservation mosaics, and birds in the Critically Endangered category in the Madidi-Tambopata mosaic. Together these analyses underline the significant contribution of the conservation mosaics supported by the Gordon and Betty Moore Foundation towards the conservation of the outstanding biodiversity value of the Amazon.

Key Words: Amazon basin, amphibians, reptiles, mammals, birds, conservation mosaics, Gordon and Betty Moore Foundation 


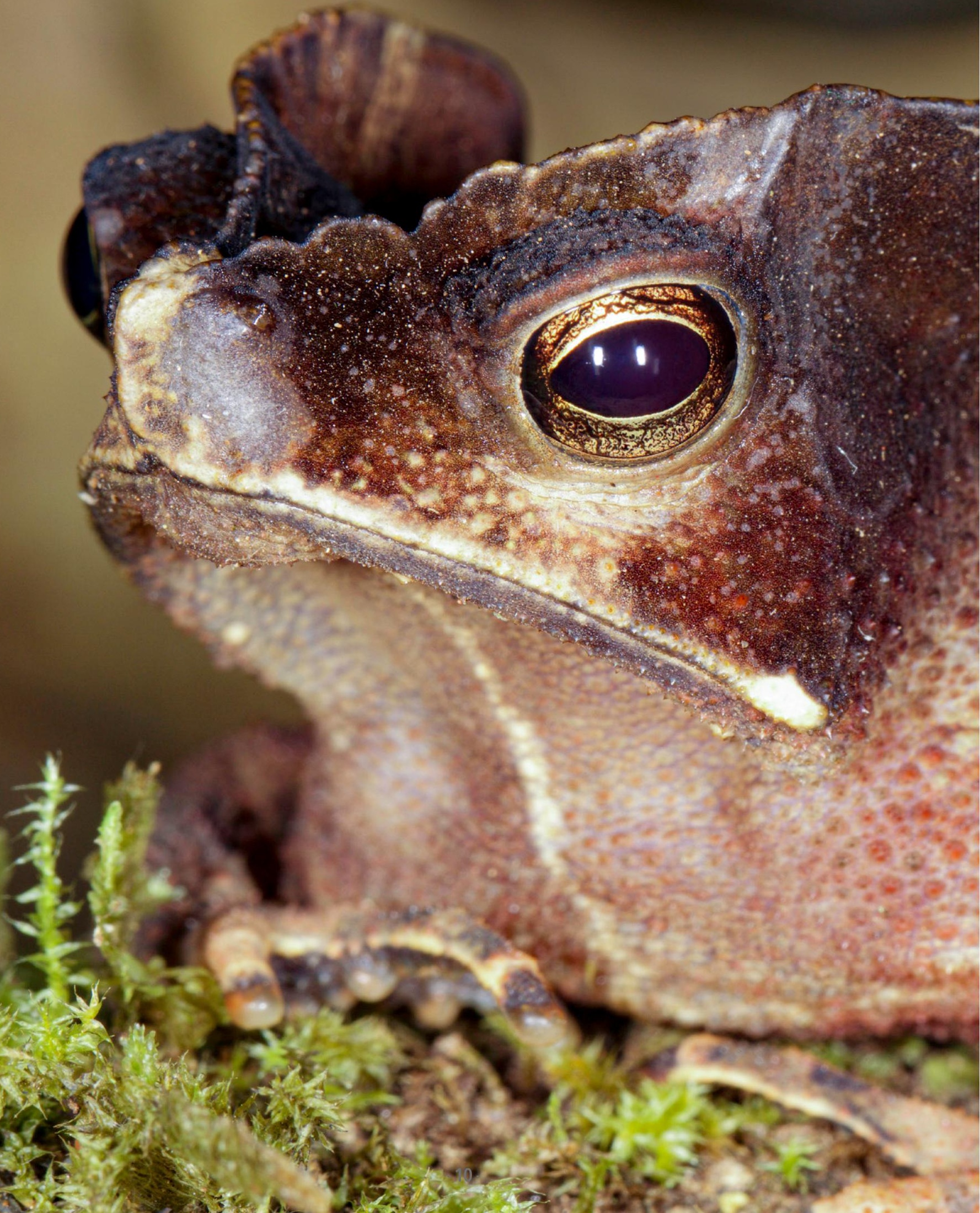




\section{INTRODUCTION}

Biodiversity or biological diversity are terms that define the variation in all the forms of life on planet earth (Gaston \& Spicer 2004; Colwell 2009). This comprises the appearance, structure and function of genes, species and ecosystems, which are organized in spatial and temporal patterns (Gregorius et al. 2003; Colwell 2009; Minteer et al. 2018). Species diversity, or the number of biological elements coexisting in a given area, is the most commonly used element for conservation purposes (Moreno 2001; Moreno et al. 2011; Socolar et al. 2015).

From a global perspective the tropics harbor the greatest biological diversity and endemism (Myers et al. 2000; Hoorn et al. 2010; Jenkins et al. 2013). The tropics cover just $10 \%$ of land, but harbor $91 \%$ of the world's birds, $83.2 \%$ of amphibians, 77\% of mammals and 75\% of plants and insects (PNUMA 2010; Barlow et al. 2018). The Amazon in the Neotropics has an enormous variety of habitats and aquatic and terrestrial species (Latrubesse et al. 2017). Unique characteristics such as the geographical barrier of the Andes and the variety of forests, wetlands and other habitats have resulted in extremely high levels of biodiversity and endemism in the Amazon (Valencia et al. 1994; Dirzo \& Raven et al. 2003; Hutter et al. 2013; De Oliveira et al. 2016; Kolář et al. 2016).

The extraordinary concentration of species in the Amazon basin is mirrored by a diversity of crucial ecosystem services, such as timber, food, water, energy, nutrient recycling, and others (Foley et al. 2007; Tilman et al. 2011; Sobral et al. 2017; Horn et al. 2018), which benefit millions of people (Horn et al. 2018; Minteer et al. 2018; Vieira et al. 2018), providing environmental services not only for the Neotropical region, but also for the world (Castro \& Riega-Campos 2014).

The Amazon basin is also home to approximately 350 indigenous groups whose territories cover $28.1 \%$ of the basin in Bolivia, Brazil, Colombia, Ecuador, Peru and Venezuela (RAISG 2016; Prüssmann et al. 2017; Strelneck \& Vilela 2017). High human cultural diversity within the indigenous territories is associated with high biodiversity concentrations, and together with protected areas, these management units play an important role in protecting the Amazon biome and the planet (RAISG 2016; Prüssmann et al. 2017; Strelneck \& Vilela 2017).

Anthropogenic activities outside conservation units (protected areas and indigenous territories) in the Amazon are responsible for the loss of biodiversity at an unprecedented rate (Peres 1990, 2007; Foley et al. 2007; Hoorn et al. 2010; Canale et al. 2012; Laurance et al. 2014; Purvis et al. 2018). In the face of imminent and ongoing changes to Amazon forests and waterways, the need to identify priority biodiversity conservation areas is paramount. One approach is to identify areas with high concentrations of species and endemism. For example, the "hotspots" proposed by Myers et al. 
(2000) have become a global conservation reference (Sloan et al. 2014; Roll et al. 2017), encouraging donors such as the Gordon and Betty Moore Foundation to implement conservation efforts in areas of high biodiversity and endemism, in particular with landscape and mosaic conservation strategies in the Amazon and beyond (Myers et al. 2000).

The Gordon and Betty Moore Foundation has implemented an AndesAmazon Initiative, supporting biodiversity conservation efforts by communities, governmental authorities and non-governmental institutions for more than fifteen years, implementing twelve conservation mosaics distributed in Bolivia, Brazil, Colombia, Ecuador and Peru in areas with hypothesized high biodiversity concentrations (Castro \& RiegaCampos 2014; Strelneck \& Thais Vilela 2017; Gullison \& Hardner 2018).

For the design of informative scenarios regarding global biodiversity it is important to recognize that biodiversity varies across habitat types, as well as between different taxonomic groups such as amphibians, mammals, insects or plants (Wolters et al. 2006). It is therefore crucial to evaluate multiple taxonomic groups when considering spatial variations in biological diversity, especially when identifying priority conservation areas (Wolters et al. 2006; Quan et al. 2018).

This study aims to demonstrate the incredible biodiversity value of the Amazon basin and the contribution of twelve conservation mosaics supported by the Gordon and Betty Moore Foundation in conserving biodiversity, with an emphasis on the four terrestrial vertebrate groups: amphibians, reptiles, birds and mammals. In so doing, this analysis intends to demonstrate the relevance of existing conservation efforts, as well as influence future decisions and actions in the conservation mosaics. 


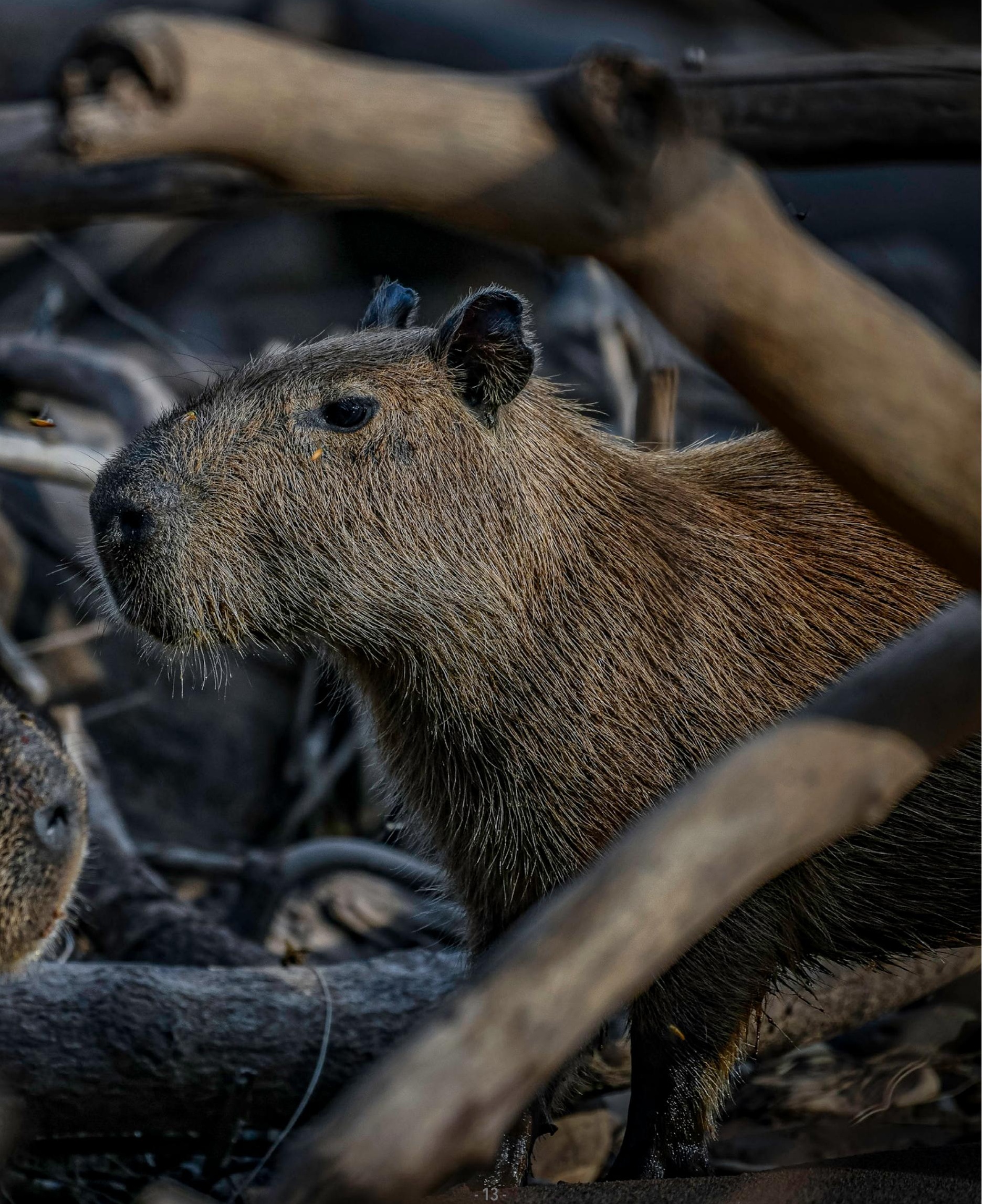




\section{Agamia agami}

( 10 thay 218,6 (1) irise ing? 4.2 is:

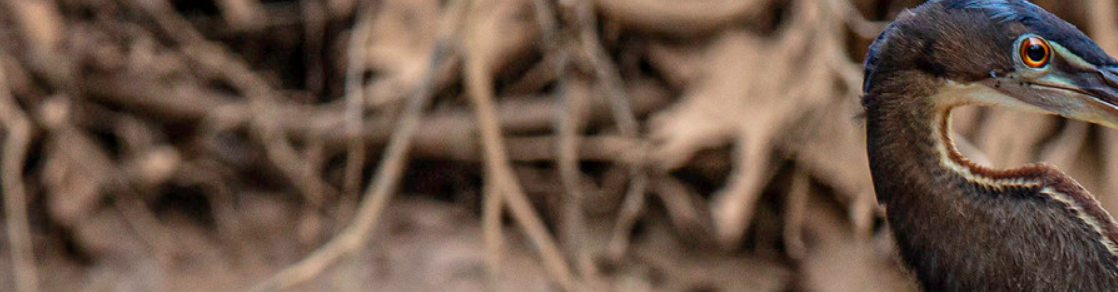

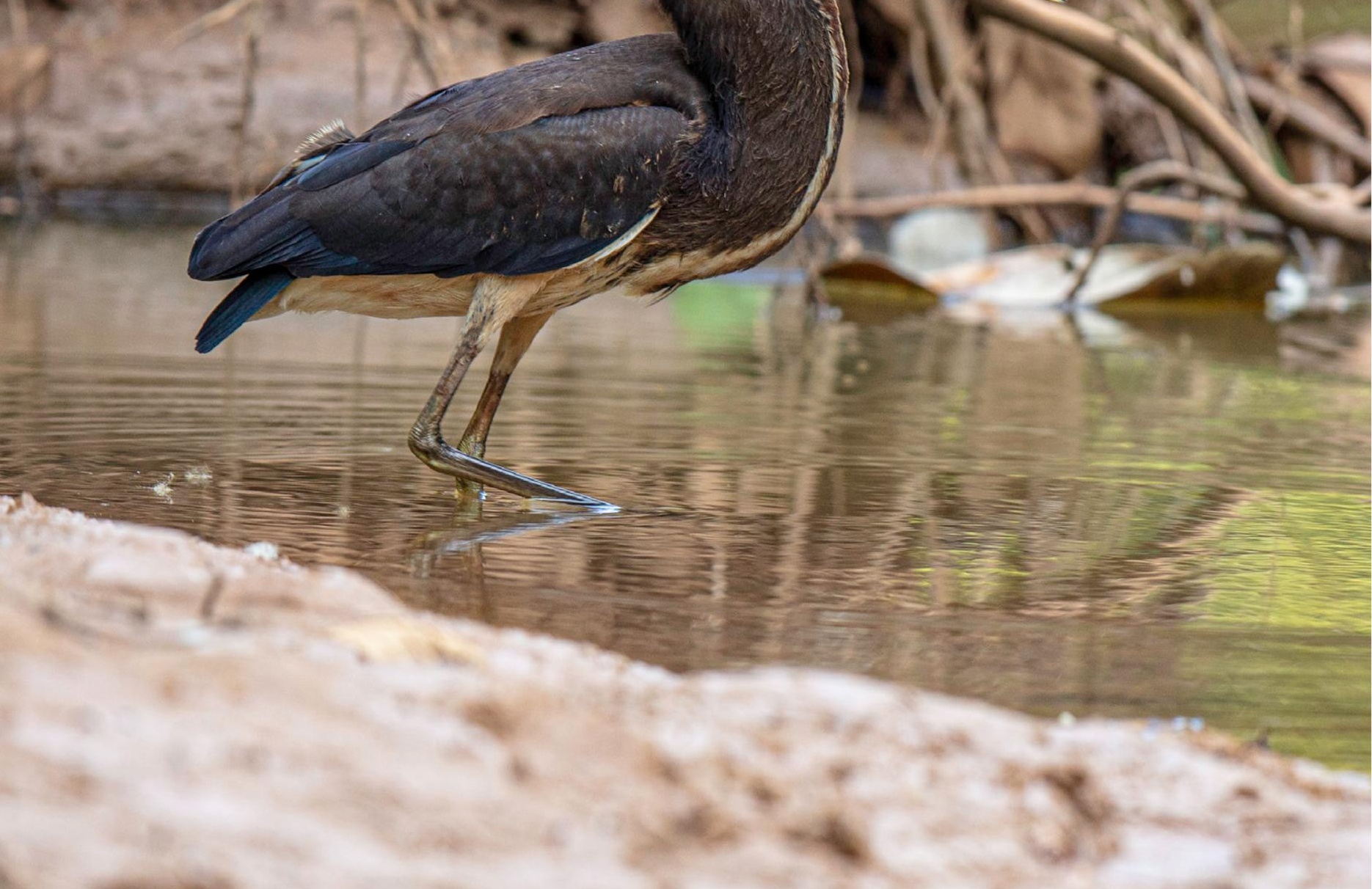
sas:

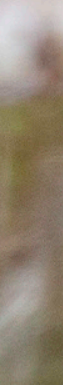




\title{
GOALS \& OBJECTIVES
}

\author{
i. Goal
}

Demonstrate the extraordinary value of the Amazon basin towards biodiversity conservation through analyses of four terrestrial vertebrate groups: amphibians, reptiles, birds and mammals.

\section{ii. Objective}

Demonstrate the contribution of the conservation mosaics in the Amazon basin supported by the Gordon and Betty Moore Foundation for biodiversity conservation in the Amazon.

\section{iii Specific objectives}

- Determine expected and confirmed species of amphibians, reptiles, birds and mammals in the twelve conservation mosaics supported by the Andes-Amazon Initiative of the Gordon and Betty Moore Foundation.

- Elaborate maps of species richness for three vertebrate groups (birds, amphibians and mammals) for South America at $1 \mathrm{~km}^{2}$ scale. 


\section{STUDYAREA}

The study area is the Amazon basin, the most extensive tropical forest and the largest freshwater hydrological system in the world, with particular emphasis on the conservation mosaics supported by the Gordon and Betty Moore Foundation (Table 1; Figure 1). The Amazon basin is shared by nine countries (Brazil, Bolivia, Peru, Ecuador, Colombia, Venezuela, French Guiana, Guyana, and Suriname) and is inhabited by 33 million people including 350 indigenous groups (Prüssmann et al. 2017).

Table 1. Conservation Mosaics supported by the Gordon and Betty Moore Foundation in the Amazon Basin

\begin{tabular}{|c|c|}
\hline Mosaic & Countries \\
\hline Chiribiquete-Caqueta & Colombia \\
\hline Yasuni-Pastaza & Ecuador, Peru \\
\hline Yavari-Samiria & Peru \\
\hline Ampiyacu & Peru \\
\hline Upper Purus & Brazil, Peru \\
\hline Madidi-Tambopata & Bolivia, Peru \\
\hline Itenez-Rondonia & Bolivia, Brazil \\
\hline Calha Norte & Brazil \\
\hline Xingu & Brazil \\
\hline Lower Rio Negro & Brazil \\
\hline Upper Rio Negro & Colombia, Brazil \\
\hline Madeira & Brazil \\
\hline
\end{tabular}

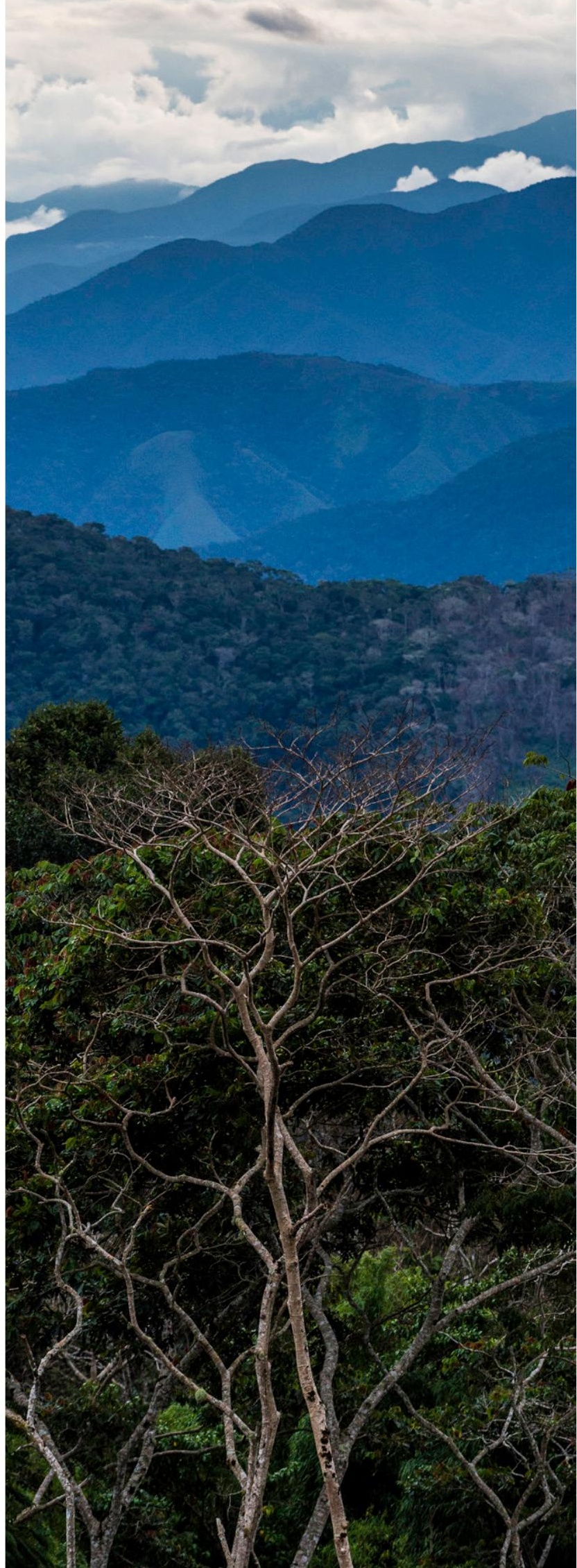




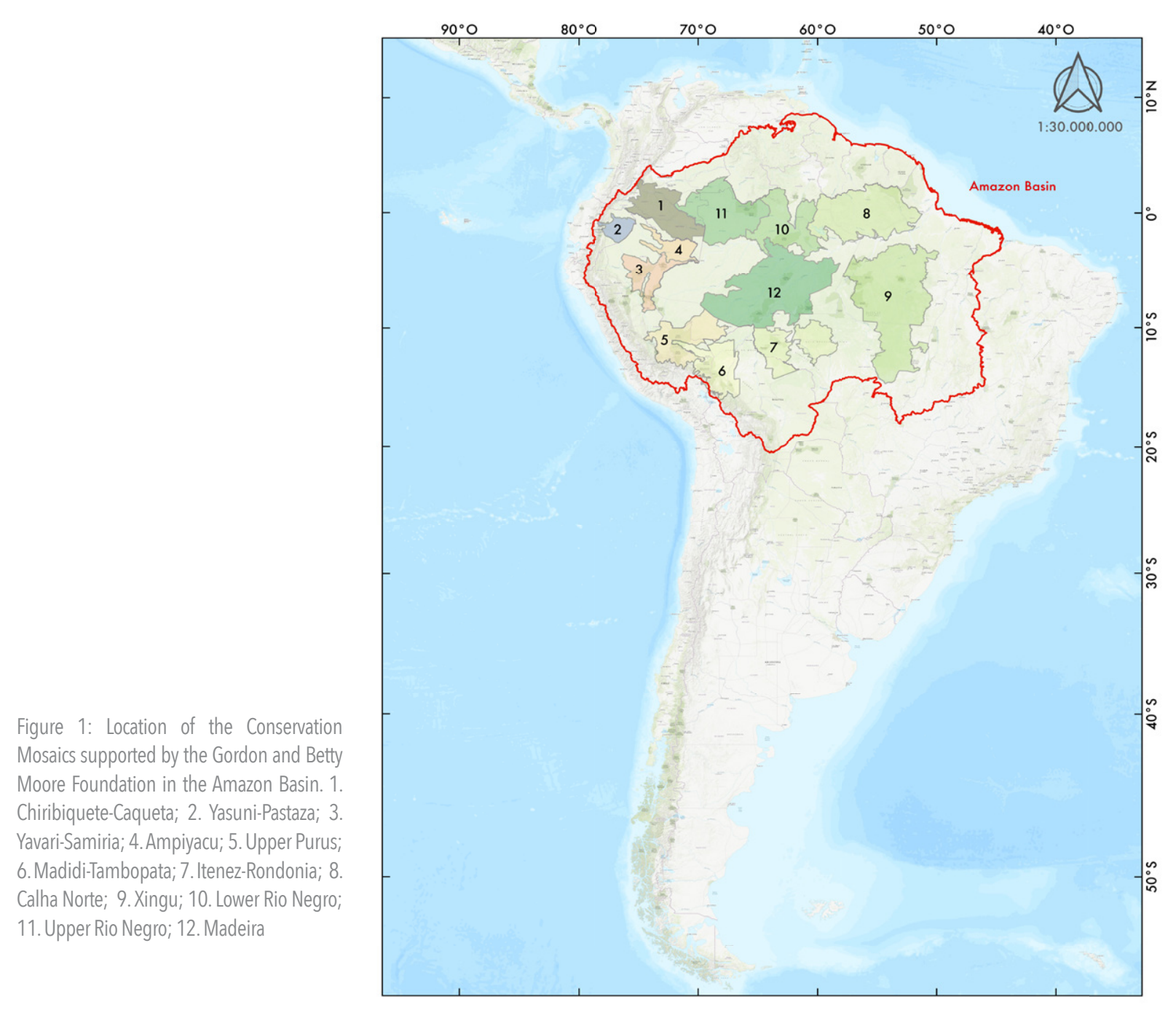

\section{METHODS}

To generate expected and confirmed species lists for amphibians, reptiles, birds and mammals for the twelve conservation mosaics supported by the Andes-Amazon Initiative of the Gordon and Betty Moore Foundation, we performed the following four steps: 1) taxonomic revision and update for terrestrial vertebrate species present in South America and the Amazon basin, 2) creation of distribution polygons for amphibian, reptile and mammal species not evaluated by the International Union for the Conservation of Nature (IUCN), 3) information search for species distribution from the IUCN (for expected species) and species databases (for confirmed species), and 4) identification of expected and confirmed species for the twelve mosaics. This analysis is a fine-scale 1 $\mathrm{km}^{2}$ effort which uses a standardized and updated dataset for all four terrestrial vertebrate groups across the Amazon. It cannot and should not replace on-the-ground field work to improve knowledge for individual protected areas and indigenous territories, but in the meantime, it does provide the best theoretical species lists available for each management unit or conservation mosaic. 


\section{i. Taxonomic revision and update for amphibians, reptiles, birds and mammals}

In order to compare the number of species present in South America and the Amazon basin, we first standardized taxonomic species lists for each terrestrial vertebrate group. For taxonomic updates we used official taxonomic platforms for each vertebrate group: AmphibiaWeb (https://amphibiaweb.org), Amphibian Species of the World (http://research.amnh.org/herpetology/ amphibia/index.html), for amphibians, the Reptile Database (http://www.reptile-database.org) for reptiles, IUCN-BirdLife (http:// datazone.birdlife.org/species/requestdis) and South American Classification Committee(http://www.museum.Isu.edu/ Remsen/ SACCBaseline.htm) for birds, and Mammal Diversity Database (https://mammaldiversity.org) and specific sources for mammals, as well as a global taxonomic source: Taxonomic Information System IT IS (https://www.itis.gov). With the exception of mammals, these websites constantly update taxonomy, providing species lists for each country.

Additionally, to determine the taxonomy for amphibians and reptiles we consulted scientific articles and previously cited websites. For mammals firstly we constructed a species list for South America using recent species lists for Ecuador (Tirira 2018; Ron et al. 2019 -Bioweb), Colombia (Ramírez-Chaves et al. 2016), Venezuela (Sánchez \& Lew 2012), Argentina (Teta et al. 2018), French Guiana, Guyana, and Suriname (Lim 2016), Argentina, Brazil (Paglia et al. 2012), and Bolivia (Aguirre et al. 2019) and the IUCN South America species list. We then complemented and update taxonomies using the Mammal Diversity Database (2019), and 
Patton et al. (2015) for rodents, Rowe \& Myers (2019) for primates and scientific articles published by December 2018 regarding newly described species.

\section{ii. Creation of distribution polygons for amphibian, reptile and mammal species not evaluated by the IUCN}

For amphibian, reptile and mammal species from the Amazon basin that were either not evaluated by the IUCN or were not considered in a threatened category, using scientific literature and webpages we produced distribution polygons using Quantum GIS. Similarly, for newly described species we created distribution polygons by creating a $10 \mathrm{~km}$ buffer around the original collection site.

Nevertheless, in some cases species and even genera remain in taxonomic revision or require major research to confirm taxonomies, and therefore are lacking distributional polygons, underlining that this analysis will need to be updated into the future. 
iii. Identification of expected species in the twelve conservation mosaics supported by the Gordon and Betty Moore Foundation

Geospatial information on amphibian, reptile and mammal species distributions was downloaded from the IUCN (IUCN 2018, https://www. iucnredlist.org) in November 2018 (reptiles in January 2019), and bird distributions were downloaded from Birdlife International, through the IUCN portal. Scientific names were updated using the updated taxonomic lists.

The expected species analysis used the IUCN geospatial information about species distribution (Table 2) to predict presence for amphibians, reptiles, birds and mammals (see Appendix 1 for details). Predicted presence within the conservation mosaics supported by the Gordon and Betty Moore Foundation was determined using the intersection geoprocessing tool in Quantum GIS.

Table 2. Number of Vertebrate Species in South America

\begin{tabular}{|c|c|c|c|}
\hline Vertebrate Group & Geospatial Source & $\begin{array}{l}\text { Number of } \\
\text { Species }\end{array}$ & $\begin{array}{c}\text { Total Number of } \\
\text { Species with Geospatial } \\
\text { Information }\end{array}$ \\
\hline \multirow{2}{*}{ Amphibians } & Amphibian Species of the World & 2,921 & \multirow{2}{*}{$2,873^{*}$} \\
\hline & IUCN & 2,474 & \\
\hline \multirow{3}{*}{ Reptiles } & The Reptile Database & 2,195 & \multirow{3}{*}{$2,138^{\star}$} \\
\hline & Roll et al. (2017) & 1,977 & \\
\hline & IUCN & 7 & \\
\hline \multirow{2}{*}{ Birds } & Birdlife & 3,564 & \multirow{2}{*}{3,607} \\
\hline & IUCN-BirdLife & 3,625 & \\
\hline \multirow{2}{*}{ Mammals } & IUCN & 1,258 & \multirow{2}{*}{1,339} \\
\hline & IUCN \& other sources & 1,385 & \\
\hline
\end{tabular}

*Due to gaps in the geospatial information, we digitized additional distribution polygons (191 polygons for mammals, 399 for amphibians, 161 for reptiles). 

iv. Identification of confirmed species in the twelve conservation mosaics supported by the Gordon and Betty Moore Foundation

Confirmed species records for amphibians, reptiles, birds and mammals present in the Amazon basin were compiled in spatially explicit databases for each taxonomic group. We included all georeferenced occurrences for species in South America and the Amazon basin, based on available records in the Global Biodiversity Information Facility (GBIF: http://www.gbif.org/) platform. Additional records were systematized from Splink (http://www. splink.org.br/), Vertnet (http://www.vertnet.org/), ICMBIO (portaldabiodiversidade.icmbio.gov.br/portal/), and recent scientific articles for amphibians, reptiles and mammals. Newly described species were added to the databases, and the species lists were modified according to the taxonomic updates performed for each vertebrate group.

Initially, we obtained 276,722 amphibian records, 96,082 reptile records, and 128,922 mammal records in the Amazon basin. Subsequently, these databases were cleaned, eliminating records without coordinates, or not identified to species level, as well as records from zoological collections, fossil records and other anomalies. Data from iNaturalist was carefully revised but not included for amphibians and reptiles due to low taxonomic confidence. After the data cleaning process, in total 41,932 amphibian records remained, 19,952 reptile records, and 27,056 mammal records in the twelve mosaics. v. Contribution of the conservation mosaics supported by the Gordon and Betty Moore Foundation towards the conservation of biodiversity.

Geospatial data for the Amazon basin was downloaded from the SNAPP Western Amazon Group (Venticinque et al. 2016) and international limits from the Global Administrative Areas (GADM 2018).

Expected and confirmed species analyses for the twelve mosaics employed geospatial data on species' distribution and presence (Table 2), the Amazon Basin, international limits and the conservation mosaic limits supported by the Gordon and Betty Moore Foundation, and used the geoprocessing intersection tool in Quantum GIS.

vi. Alpha-diversity analysis for the twelve conservation mosaics supported by the Gordon and Betty Moore Foundation

To determine the areas of greatest vertebrate diversity in South America and the Amazon basin and thereby show the representativeness of the conservation mosaics supported by the Gordon and Betty Moore Foundation we described the alpha-diversity of each vertebrate group. To date global efforts to determine species concentrations have used pixels of 10 $\mathrm{km}^{2}$ or greater(Myers et al.2000, Jenkins et al. 2013, Roll et al. 2017). Here we use a finer pixel size of $1 \mathrm{~km}^{2}$. 
Geospatial information on IUCN species distributions was projected on WGS 84/World Mercator (EPSG:3395). Using the SAGA geoprocessing rasterize tool (Conrad et al. 2015), we generated raster data for each terrestrial vertebrate species using 1x1 km sized pixels, reclassifying values, where a value of 1 was assigned to pixels with presence, and 0 to those without presence.

Finally, using the geoprocessing raster calculator, we analyzed species distributions as a function of IUCN conservation state: Extinct (EX), Critically Endangered (CR), Critically Endangered \& Possibly Extinct (CR PE), Critically Endangered \& Extinct in the Wild (CR EW), Endangered (EN), Vulnerable (VU), Near Threatened (NT), Least Concern (LC), Data Deficient (DD) and Not Evaluated. For the alphadiversity analyses we summed the different conservation status raster's, with the exception of the Extinct, and Extinct in the Wild categories.

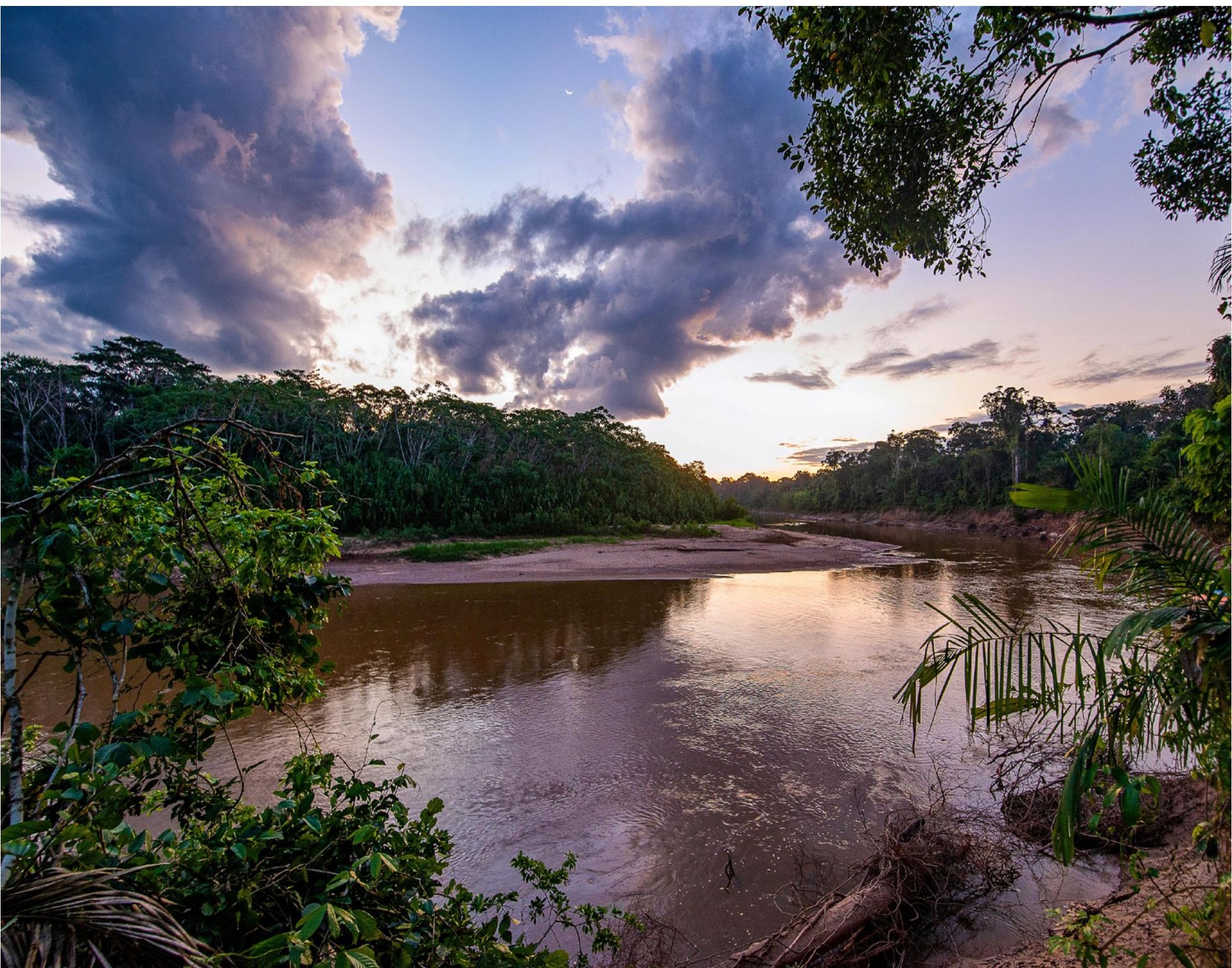


45

$10 \times 12$

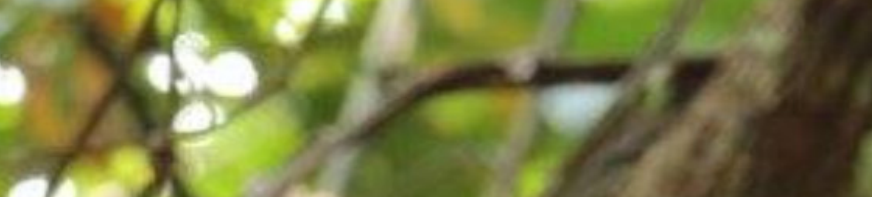
28
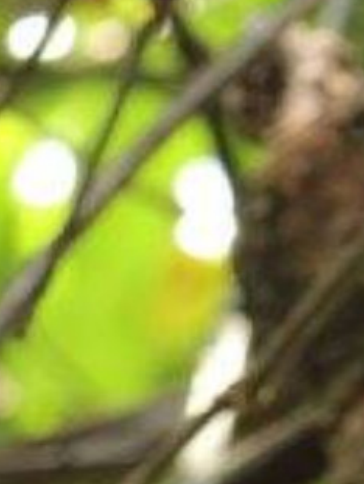

9 ant
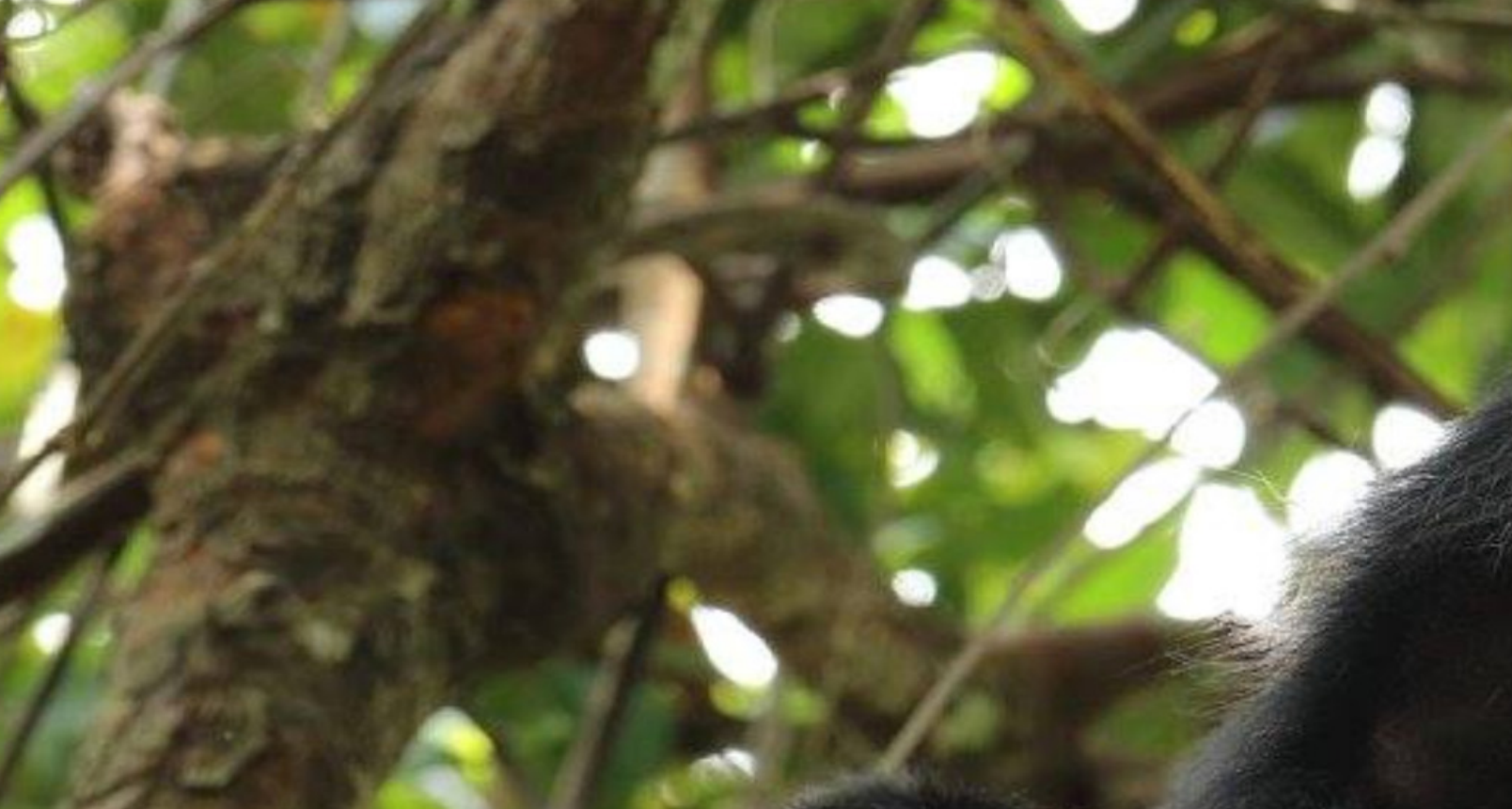

$0 \%$

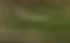

X

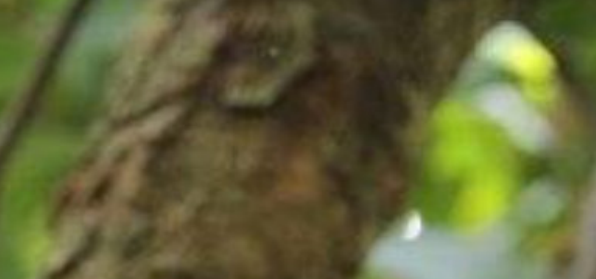

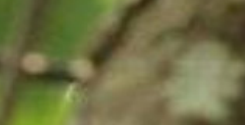

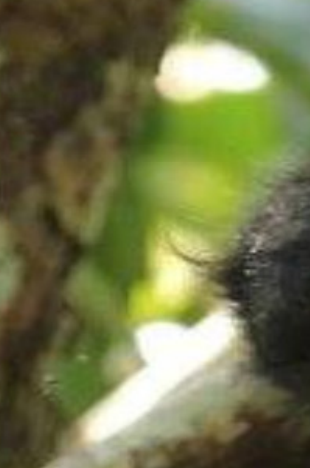

enas

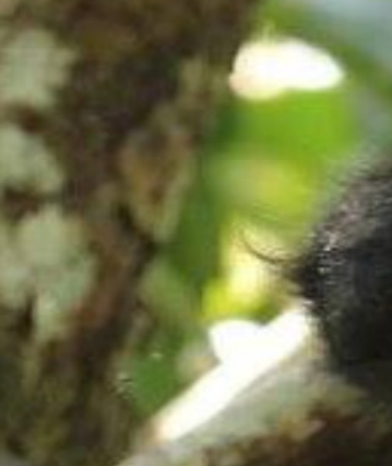

$\sin ^{2}+2$ is

$\rightarrow$

ar $e^{6}$
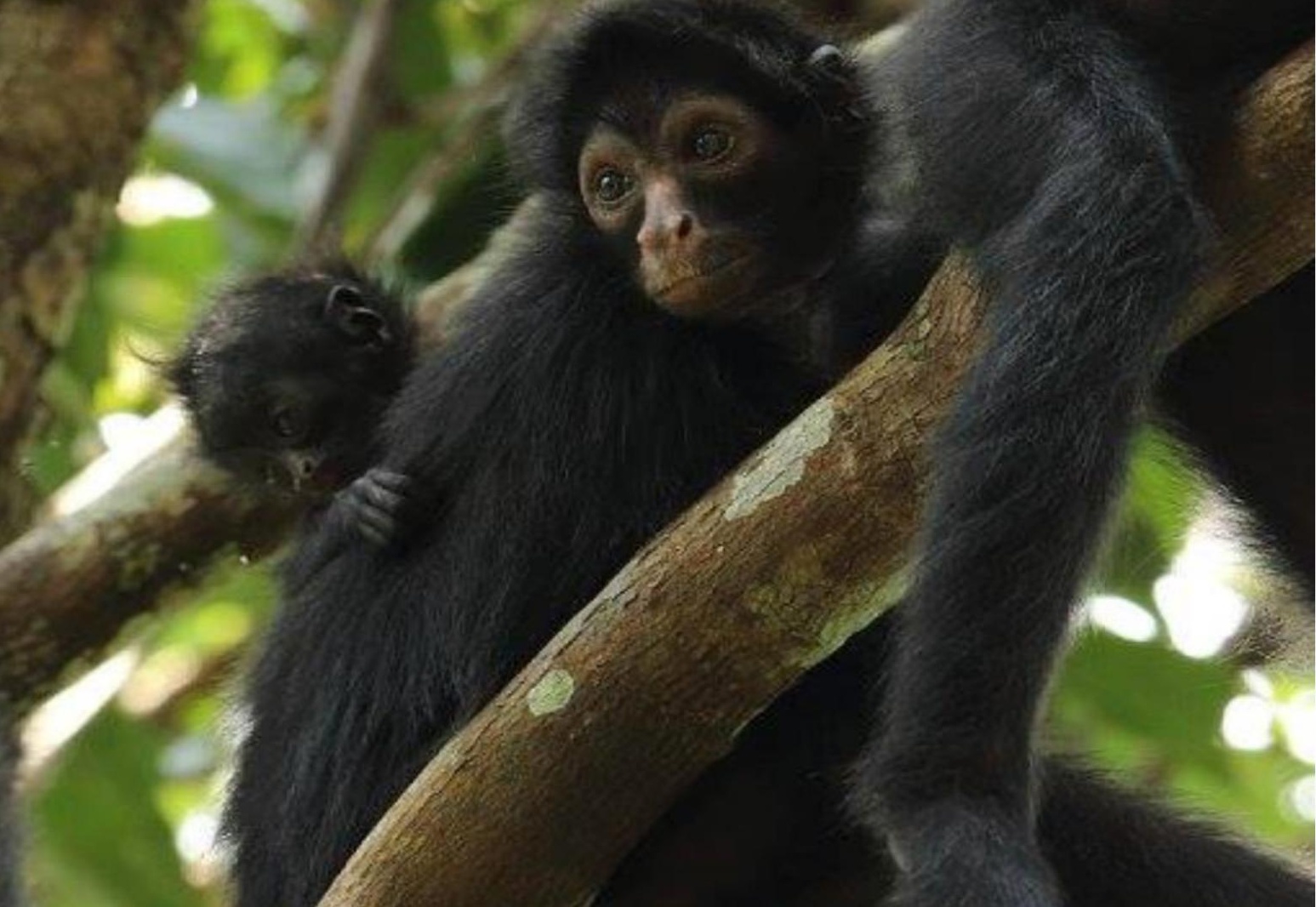


\section{RESULTS}

Firstly, we describe the biological diversity of the terrestrial vertebrate groups in the twelve conservation mosaics supported by the Gordon and Betty Moore Foundation, comparing expected and confirmed species. We also describe the representativeness of vertebrate diversity within the twelve conservation mosaics for the Amazon basin, South America and the world.

\section{i. Number of expected and confirmed species for} four vertebrate groups in the twelve conservation mosaics supported by Gordon and Betty Moore Foundation

The twelve conservation mosaics supported by the Gordon and Betty Moore Foundation harbor an estimated 3,836 species of amphibians, reptiles, birds and mammals, of which 3,099 species have already been confirmed within the total mosaic area. Thus, 737 species have yet to be reported by scientists, and therefore confirmed, in the twelve mosaics. The total number of expected terrestrial vertebrates in each conservation mosaic varies between 1,284 and 2,034 species (with between 430 and 1,708 species confirmed) (Figure 2). The difference in the quantity of expected versus confirmed terrestrial vertebrate species is rather consistent across the twelve mosaics(Figure 2), with the mosaics with the lowest number of expected species, such as Ampiyacu, also displaying the lowest number of confirmed species, and the mosaics with highest number of expected species, such as Madidi-Tambopata, also displaying the highest number of confirmed species. 
The mosaics in the western Amazon, particularly MadidiTambopata with 2,034 expected species (1,708 confirmed), Upper Purus with 1,972 expected species (1,747 confirmed), and Yasuni-Pastaza with 1,805 expected species $(1,470$ confirmed), are the conservation mosaics with the greatest diversity of amphibians, reptiles, birds and mammals. The other mosaics have less expected species, with rather similar numbers between 1,367 and 1,575 expected species (876 to 1,215 confirmed species), except Ampiyacu which has notably less confirmed species (565) in comparisson to expected species $(1,348)$.

Ampiyacu, Itenez-Rondonia, Calha Norte, Upper Rio Negro and Yavari-Samiria are the conservation mosaics with the greatest number of expected, but as yet unconfirmed, vertebrate species (487 to 854 species; Figure 2). In contrast, the mosaics with the least number of unconfirmed but expected terrestrial vertebrate species: Upper Purus (225 species), Madidi-Tambopata (326 species), Madeira (330 species) and Xingu (356 species).

Similarly, the expected and confirmed species data can be examined for each terrestrial vertebrate group (Figure 3), for example, between 680 and 1,240 species of birds are expected in the conservation mosaics (645 to 1,197 confirmed species), between 132 and 225 expected species of amphibians (63 to 169 confirmed species), between 197 and 271 expected species of reptiles (85 to 161 confirmed species), and between 242 and 335 expected species of mammals (106 to 264 confirmed species). Again, Madidi-
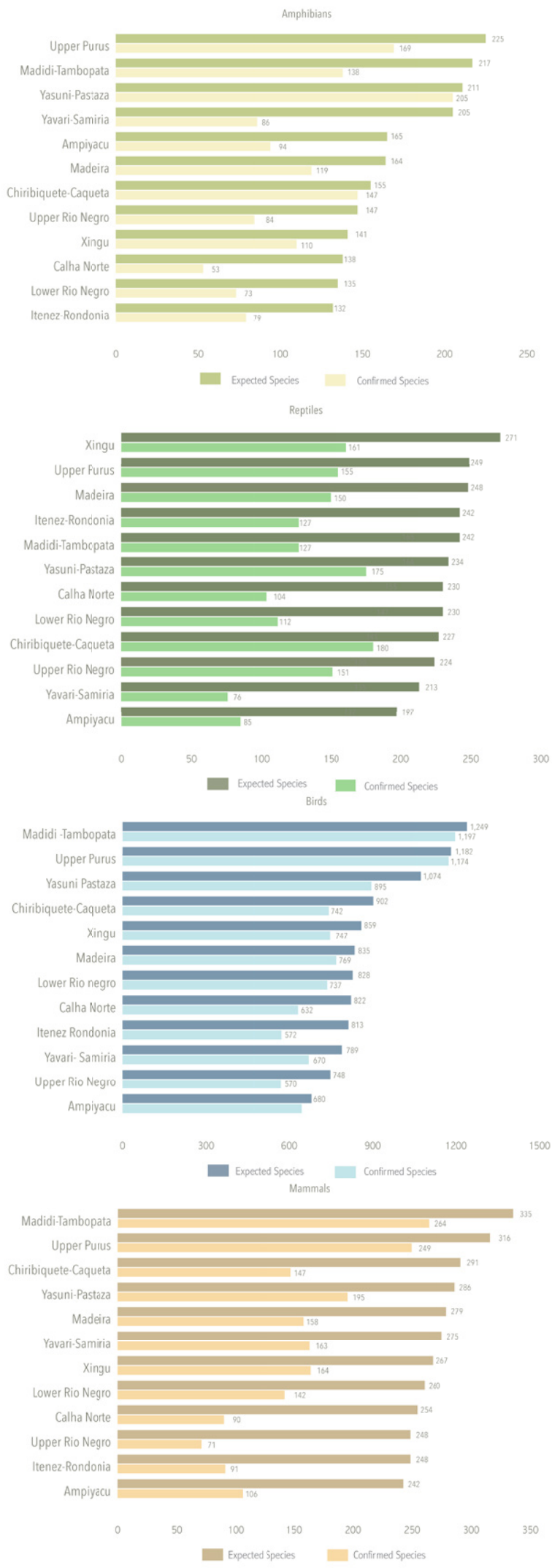

Figure 2: Number of Expected and Confirmed Species in each Vertebrate Group in the 12 Conservation Mosaics supported by the Gordon and Betty Moore Foundation 


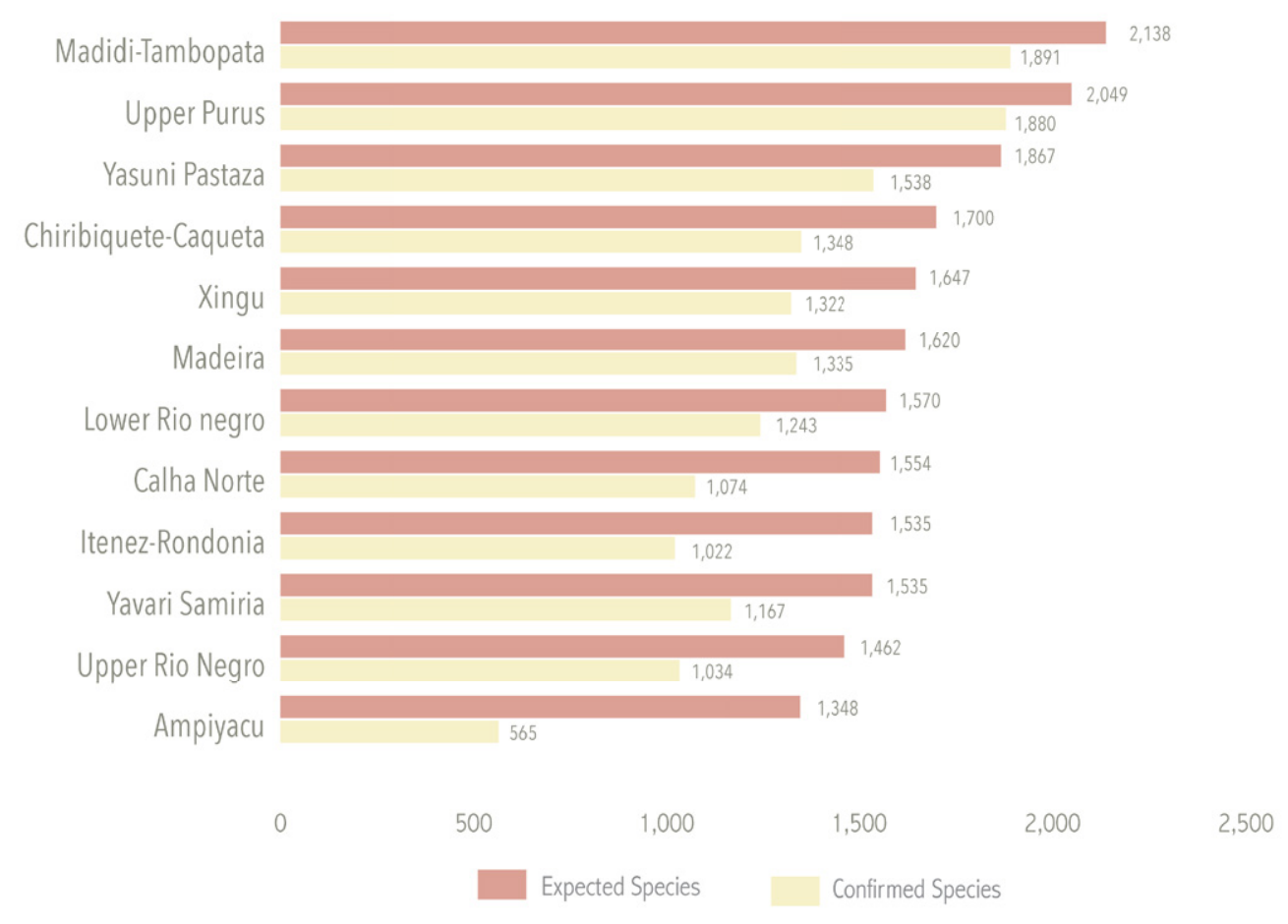

Figure 3: Number of Expected and Confirmed Species of Terrestrial Vertebrates in the 12 Conservation Mosaics supported by the Gordon and Betty Moore Foundation

Tambopata and Upper Purus are the conservation mosaics with the highest expected species numbers for birds (up to 1,240 species, with 1,197 confirmed species), amphibians (up to 225 species, with 169 confirmed species) and mammals (up to 335 species, with 264 confirmed species). Yasuni-Pastaza, Chiribiquete-Caqueta, Madeira and YavariSamiria also have high numbers of each vertebrate group, with Yasuni-Pastaza the conservation mosaic with most confirmed amphibian species, and Xingu the conservation mosaic with the highest number of expected reptile species. In contrast, Ampiyacu is the conservation mosaic with the least number of reptiles (197 expected species and 85 confirmed species), birds (680 expected species and 645 confirmed species) and mammals (242 expected species and 106 confirmed species). Upper Río Negro and ItenezRondonia also have lower expected and confirmed species for birds and mammals, and Yavari-Samiria, Upper Rio Negro and Chiribiquete-Caqueta also have lower numbers for reptiles. Finally, Itenez-Rondonia, Calha Norte and Lower Rio Negro have the lowest number of expected and confirmed amphibian species. 


\section{ii. Representativeness of biological diversity of the twelve conservation mosaics supported by the Gordon and Betty Moore Foundation}

The Amazon basin is home to 5,756 species of the four terrestrial vertebrate groups (Figure 4), representing $56.94 \%$ of all South American species (10,108 species). The twelve conservation mosaics cover $53.84 \%$ of the Amazon basin, and are expected to harbor 3,836 species of amphibians, reptiles, birds and mammals, representing $66.64 \%$ of Amazon species. The 3,099 terrestrial vertebrate species confirmed as present within the twelve conservation mosaics to date represent $53.84 \%$ of Amazon species. The twelve conservation mosaics occupy $22.7 \%$ of the continent and harbor $37.95 \%$ of all South American amphibians, reptiles, birds and mammals. The confirmed species make up $30.66 \%$ of South American amphibians, reptiles, birds and mammals. Globally, in 3\% of the terrestrial land cover, expected amphibian, reptile, bird and mammal diversity accounts for $10.51 \%$ of the world's diversity.

Birds have the greatest expected diversity in the twelve conservation mosaics (Figure 4) with 2,002 species $(1,695$ confirmed species), followed by mammals with 670 expected species (506 confirmed species), reptiles with 585 expected species (415 confirmed species), and amphibians with 579 expected species (483 confirmed species).
Comparing these numbers with the expected species for the Amazon basin and South America, demonstrate that $76.66 \%$ of Amazon mammals are expected to occur in the twelve conservation mosaics, with $57.89 \%$ of Amazon mammals confirmed within the mosaics to date. For birds, $80.02 \%$ of Amazon species are expected to occur in the mosaics, with $67.75 \%$ of Amazon species already confirmed within the mosaics. Indeed, the number of bird species expected to occur within the conservation mosaics represent $55.5 \%$ of all South American species ( $46.99 \%$ already confirmed), and the number of mammal species expected to occur within the conservation mosaics representing $48.38 \%$ of all South American species (36.53\% already confirmed). At a global scale, there are more marked differences in the proportions (Figure 4): the conservation mosaics are expected to harbor $18 \%$ of the worlds bird species ( $15.23 \%$ already confirmed), compared to $10.47 \%$ of the world's mammal species $(7.91 \%$ already confirmed).

For amphibians, the conservation mosaics are expected to harbor $42.89 \%$ of Amazon amphibians (35.78\% already confirmed), $19.82 \%$ of South American species, and 7.22\% of the world's amphibian species (6.02\% already confirmed). For reptiles, the values are higher for the Amazon (56.8\%) and South America (26.65\%), but lower at the global scale with $5.33 \%$ of reptiles the worlds reptiles expected to occur in the conservation mosaics ( $3.78 \%$ already confirmed). 


\section{AMAZON}

Altogether, the 12 mosaic represent $50 \%$ of Amazonian's area.

Amphibians, reptiles, birds and mammals

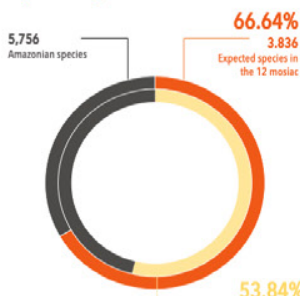

$53.84 \%$

Amphibians

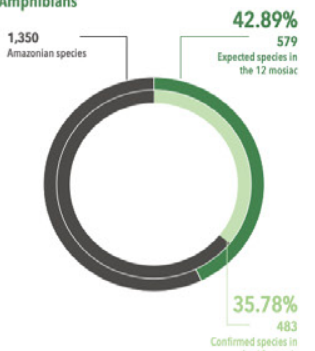

$35.78 \%$

Reptiles

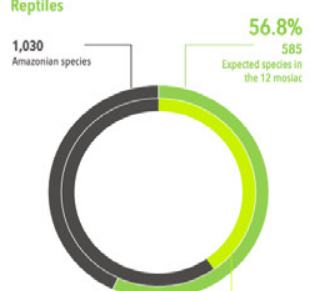

$40.29 \%$

4 speces in

Aves

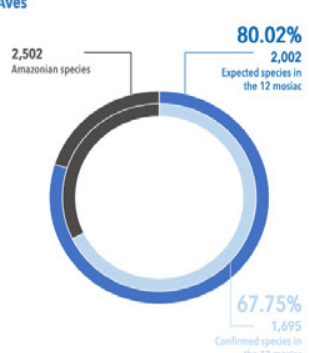

Mammals

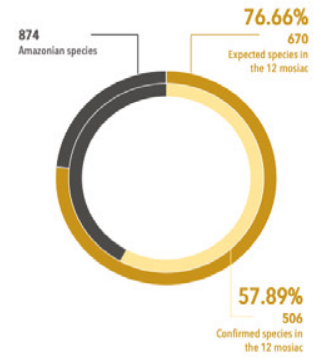

SOUTHAMERICA

WORLD

Altogether, the 12 mosaic represent $22,7 \%$ of South America's area.

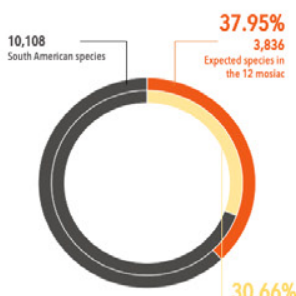

30.669
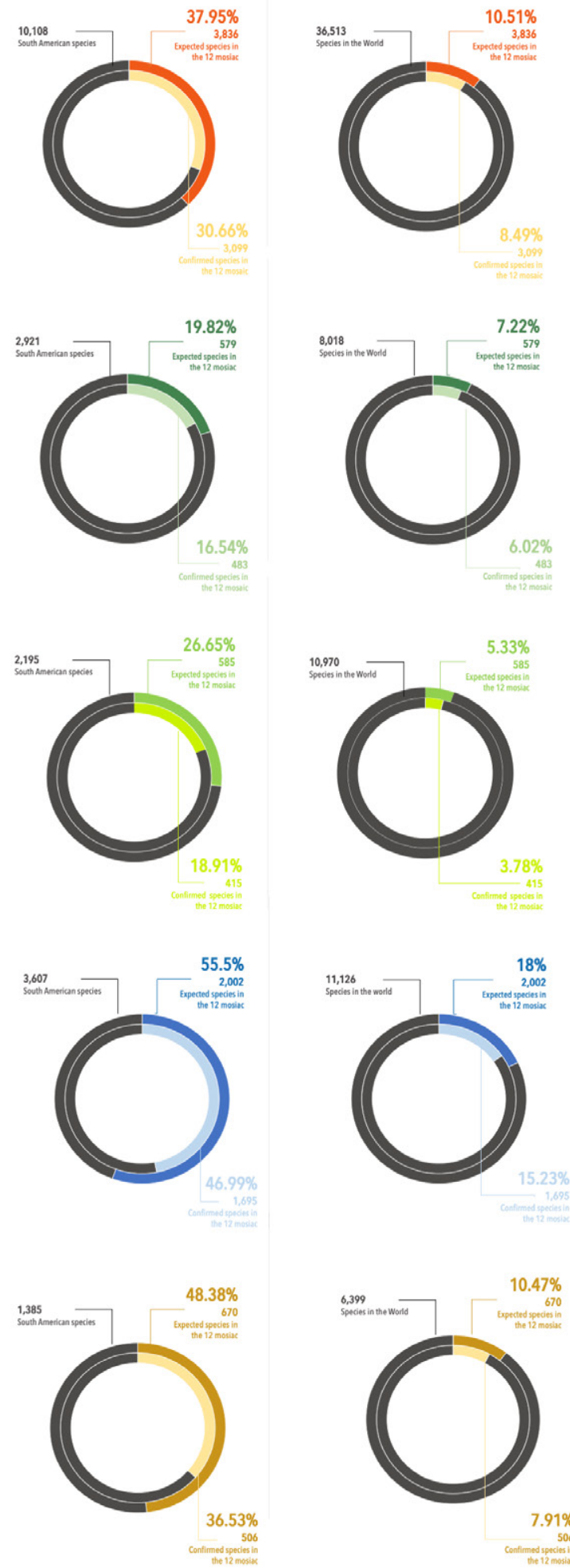

Altogether, the 12 mosaic represent $3 \%$ of Earth's surface.

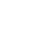




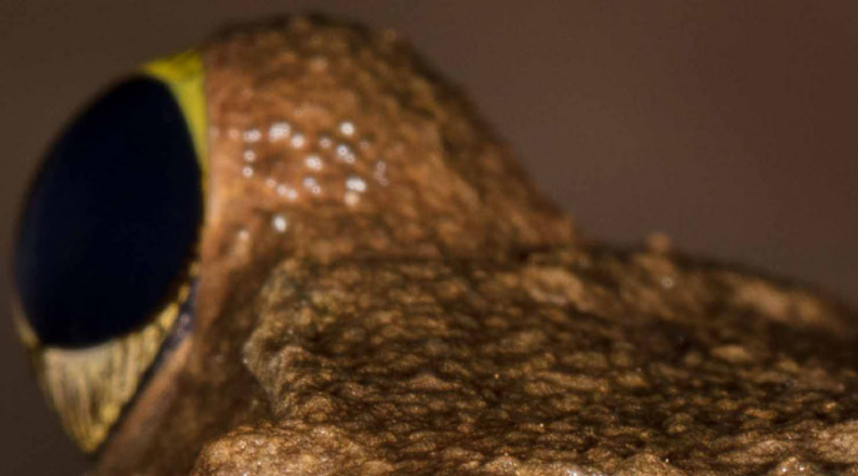

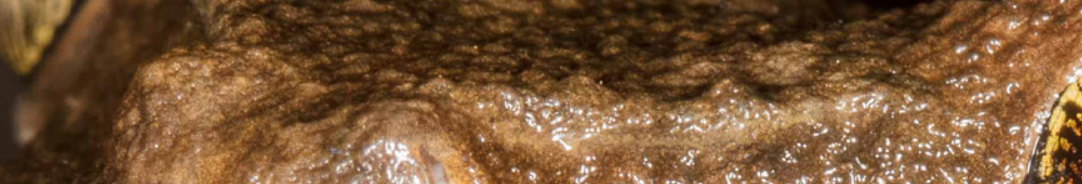

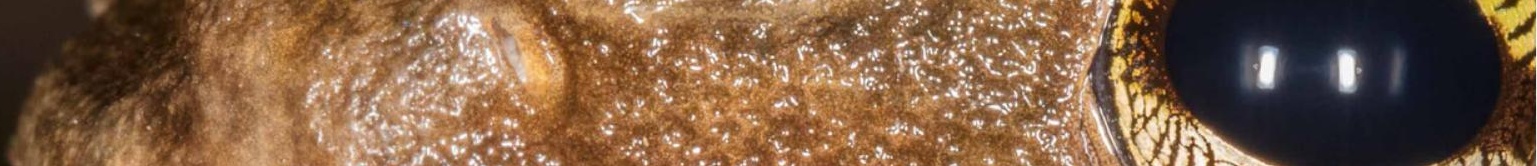

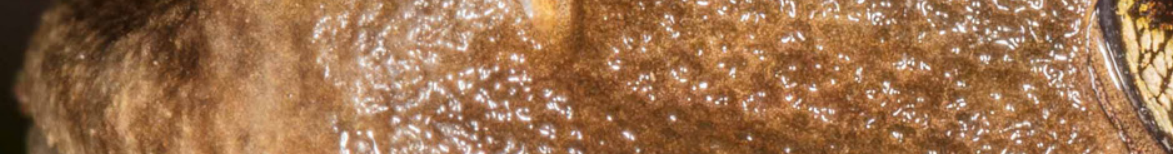

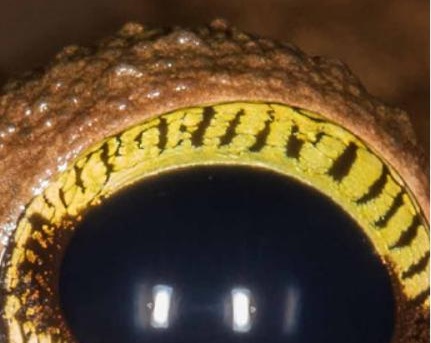

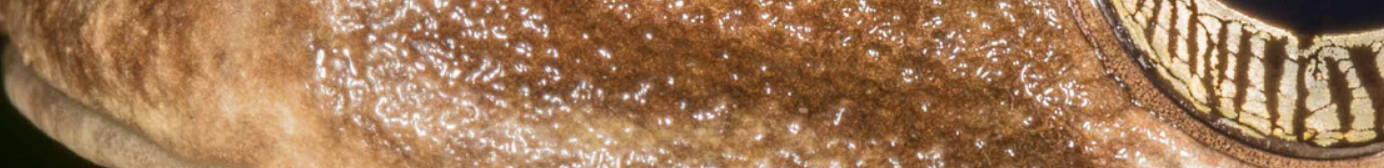

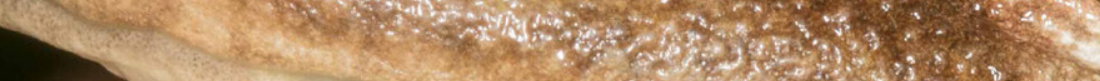
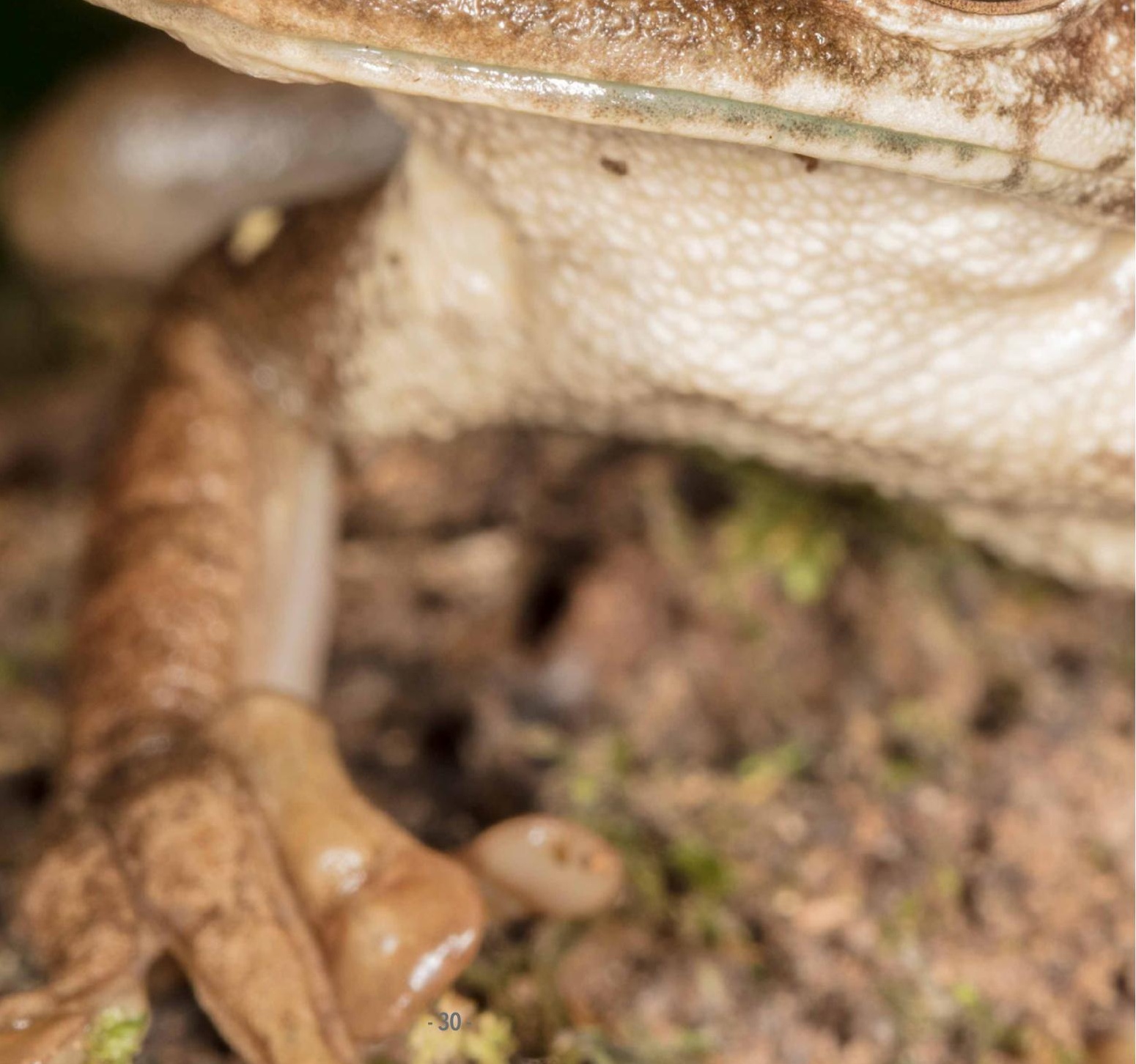


\section{iii. Contribution of the twelve conservation mosaics supported by the Gordon and Betty Moore Foundation towards biodiversity conservation}

We determined alpha-diversity across South America for amphibians, birds and mammals exclusively using available distribution polygons from the IUCN.

\section{a. Amphibians}

Amphibian species richness for South America (Figure 4) highlights the concentrations of species per $\mathrm{km}^{2}$ in the Amazon basin, especially the western Amazon where concentrations reach up to 134 species per $\mathrm{km}^{2}$. Although amphibians have the lowest number of species and the lowest levels of representativeness of the vertebrate groups within the twelve conservation mosaics supported by the Gordon and Betty Moore Foundation (Figure 3), the analysis highlights that these mosaics are placed within the highest species concentrations of amphibian diversity per $\mathrm{km}^{2}$ in South America, for example, Yasuni-Pastaza, Ampiyacu, Yavari-Samiria, and part of Upper Purus and Madeira.

The areas with the highest concentration of threatened species according to the IUCN also highlight the importance of the conservation mosaics (Figure 5). Yasuni-Pastaza and Upper Purus protect areas with between 1 and 7 Critically Endangered (CR) species per $\mathrm{km}^{2}$. Yasuni-Pastaza, Yavari-Samiria, Ampiyacu and Upper Purus have areas with concentrations of Endangered (EN) species. Other conservation mosaics have concentrations of Vulnerable (VU) species, between 1 a 15 species per $\mathrm{km}^{2}$ in Lower Rio Negro, Calha Norte, Chiribiquete-Caqueta, Upper Rio Negro, Ampiyacu, Yavari-Samiria, Yasuni-Pastaza, Upper Purus, Madidi-Tambopata and a small portion of Xingu. Given the overall importance of the Amazon for amphibian diversity, this analysis underlines the importance of the conservation mosaics for amphibian conservation, including threatened species. 


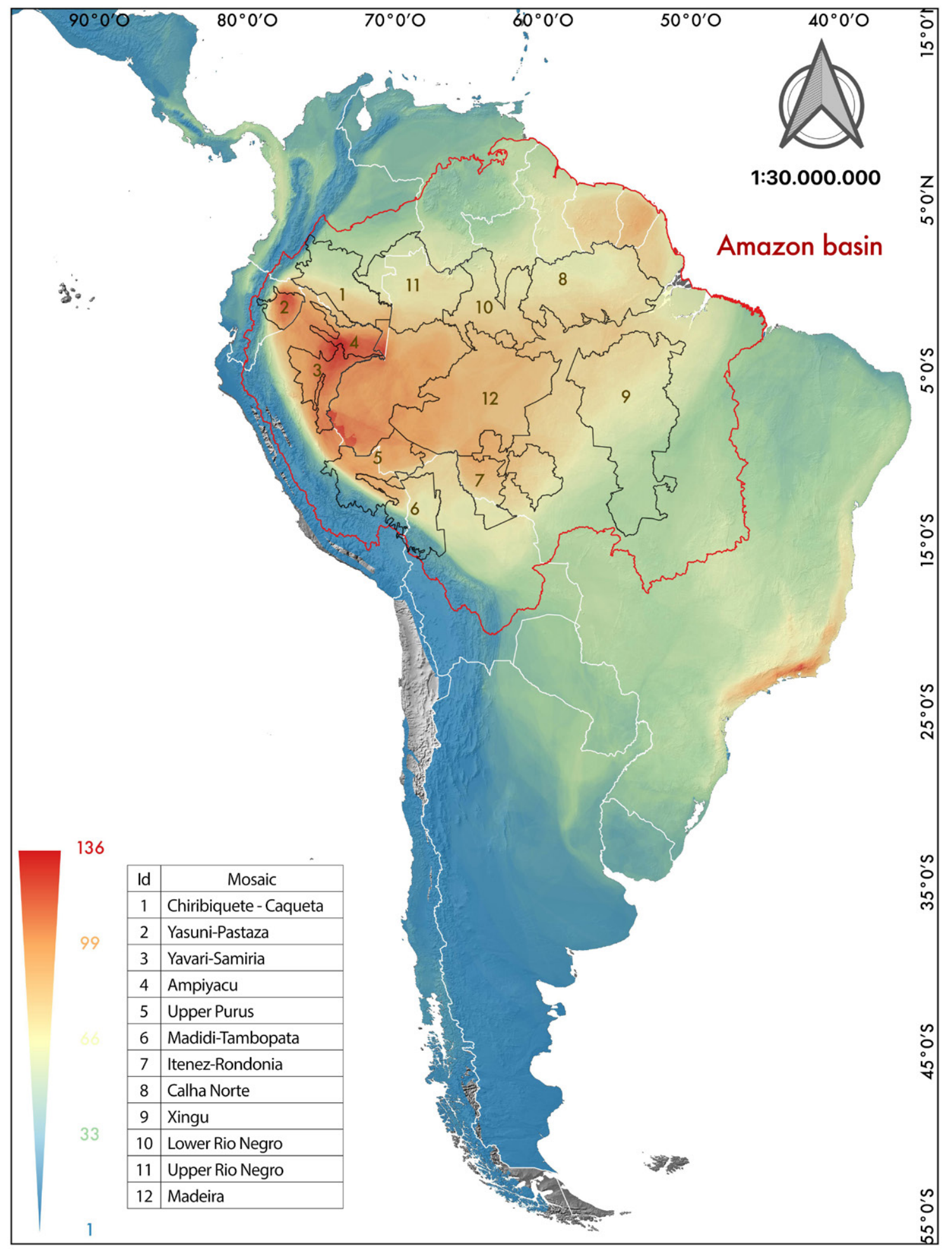

Figure 4: Amphibian Species Richness per $\mathrm{km}^{2}$ in South America 

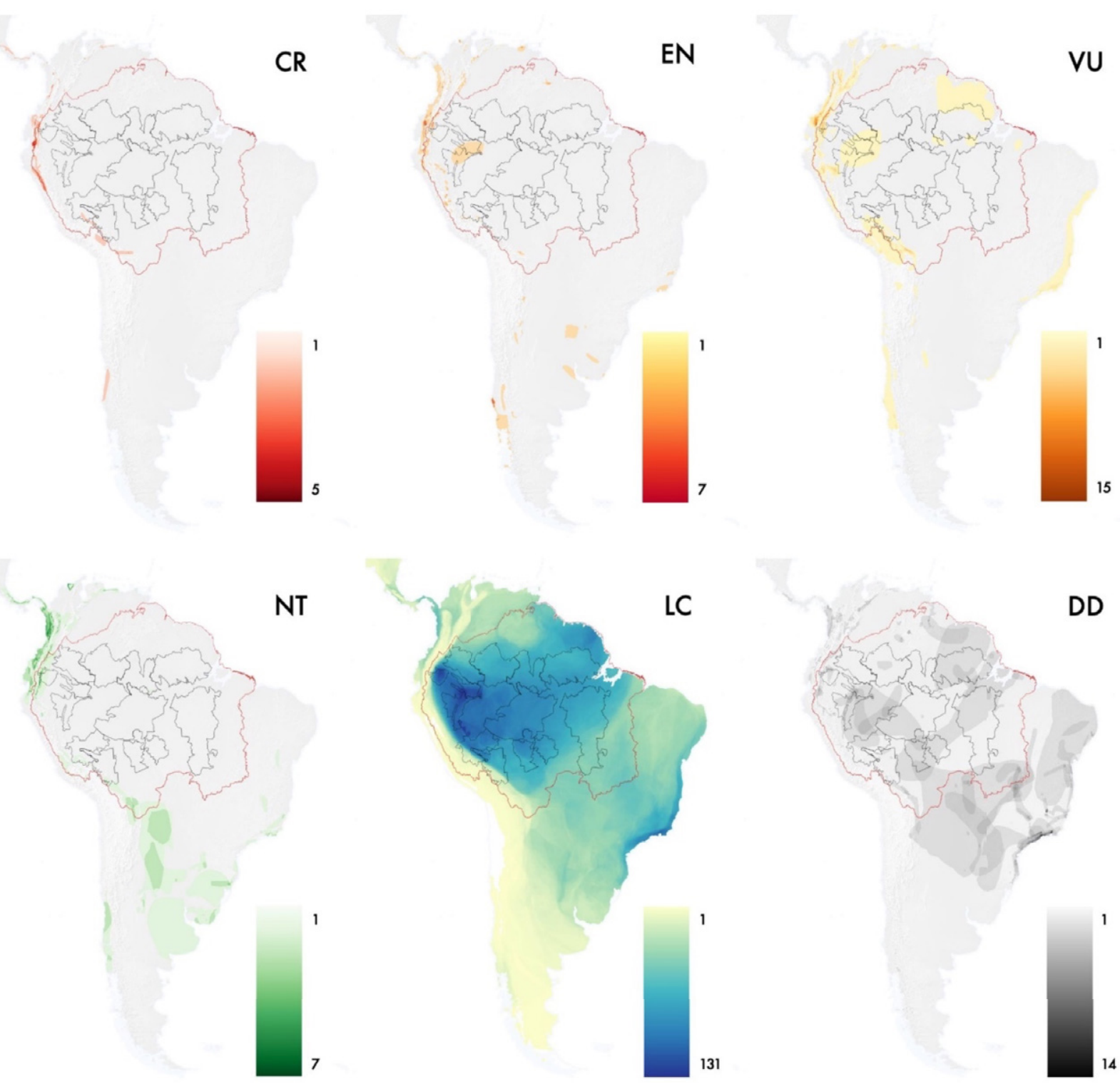

DD

Figure 5: Threatened Amphibian Species Richness per $\mathrm{km}^{2}$ in South America using IUCN (2018) Red Lists. Threatened Categories: Critically Endangered (CR); Endangered (EN); Vulnerable (VU); Near Threatened (NT); Least Concern (LC); Data Deficient(DD). 


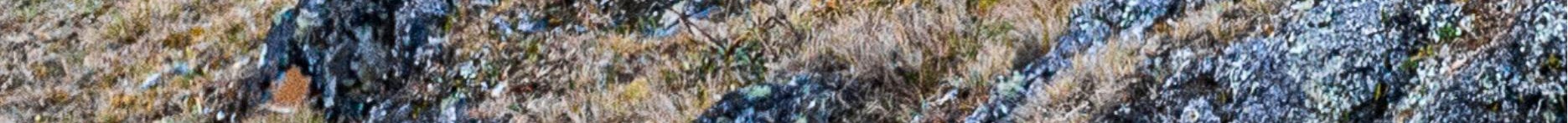

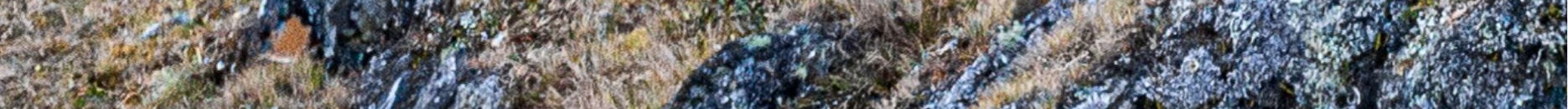

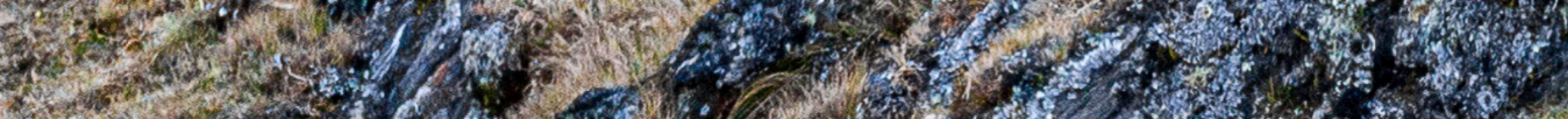
-

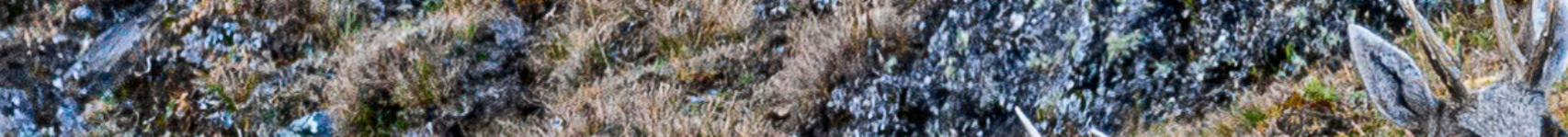

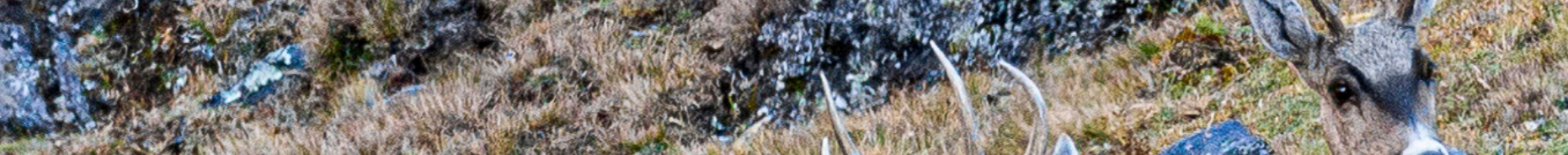

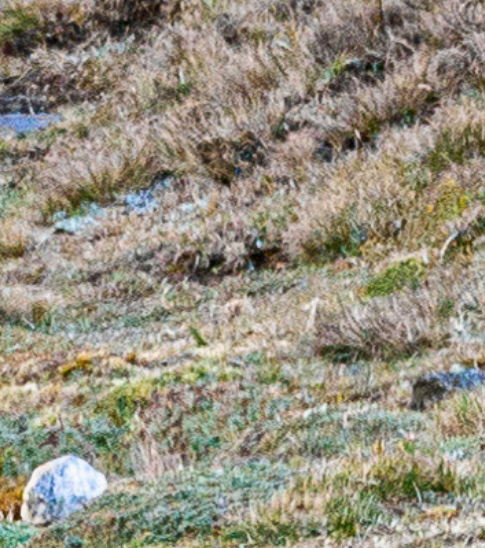

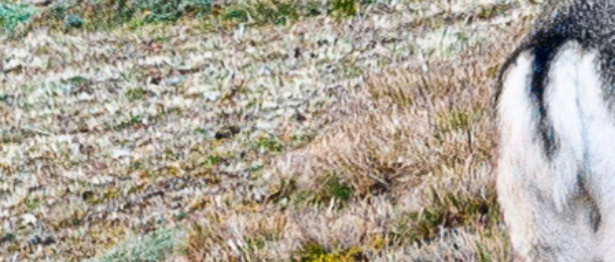

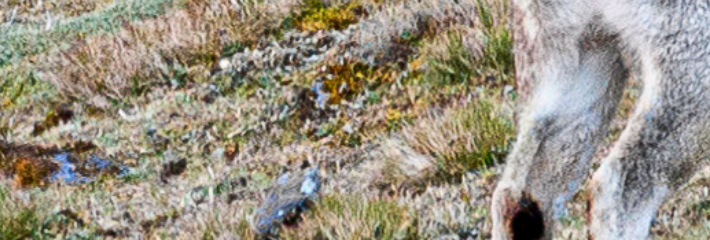

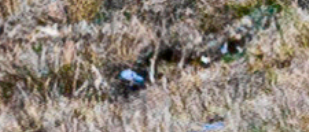

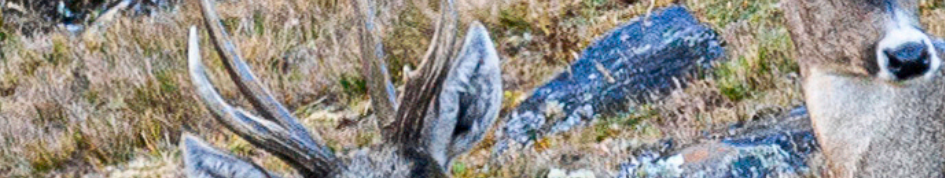

ato

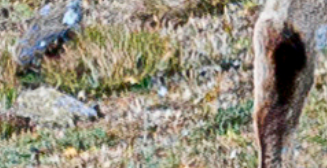

.

n. 2 (n)

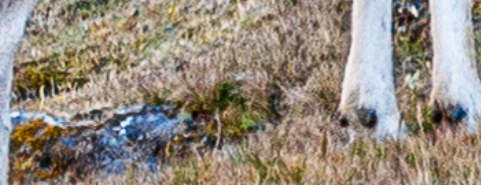

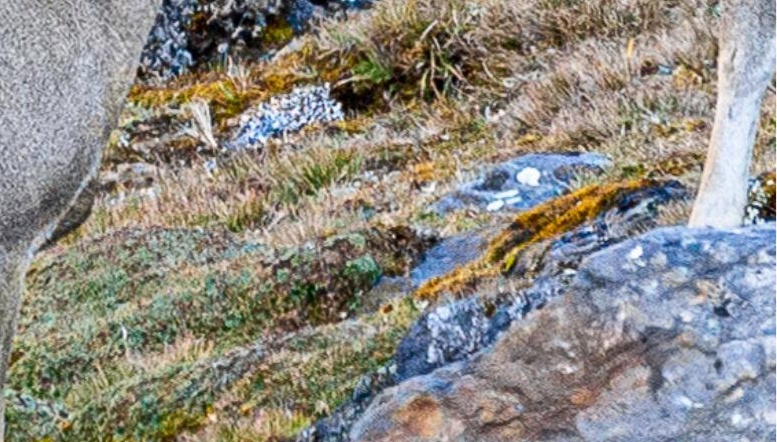

ting

6.

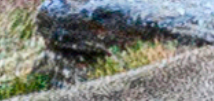

$x+5$

(1)

(3).

3. $x+2$

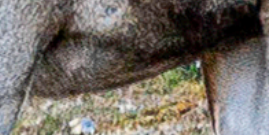

ath

a

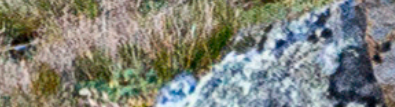

(2) $2 \sin ^{2}$

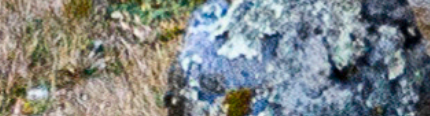

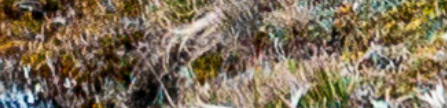

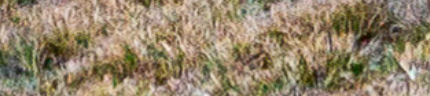

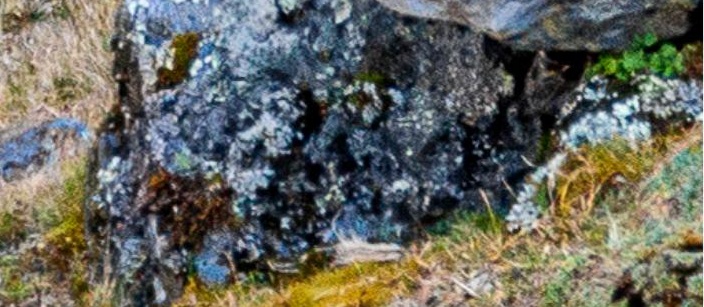




\section{b. Mammals}

The majority of the areas with the greatest concentration of mammal species in South America are found in the Amazon basin (Figure 6).Again, the areas with the highest concentrations of up to 216 species per $\mathrm{km}^{2}$ are in the Western Amazonon, highlighting the importance of the Yasuni-Pastaza, Yavari-Samiria, Ampiyacu, Upper Purus and Madidi-Tambopata conservation mosaics.

The areas with the highest concentrations of threatened mammals according to the IUCN (Figure 7) reveal that the Amazon is especially relevant for most threatened categories (LC, NT, VU, EN). Nevertheless, this is not the case for the Critically Endangered category (CR), with concentrations of up to 3 species per $\mathrm{km}^{2}$ in Colombia, Brazil and small portions of Bolivia, Ecuador, Argentina, Peru and Chile.

The Chiribiquete-Caqueta conservation mosaic has small areas with concentrations of the most threatened species, although Itenez-Rondonia, and parts of Madeira, Xingu and Calha Norte have concentrations of Endangered (EN) mammal species. Vulnerable (VU) species are concentrated in Yavari-Samiria and Calha Norte, as well as concentrations of species in the LC, NT and DD categories.

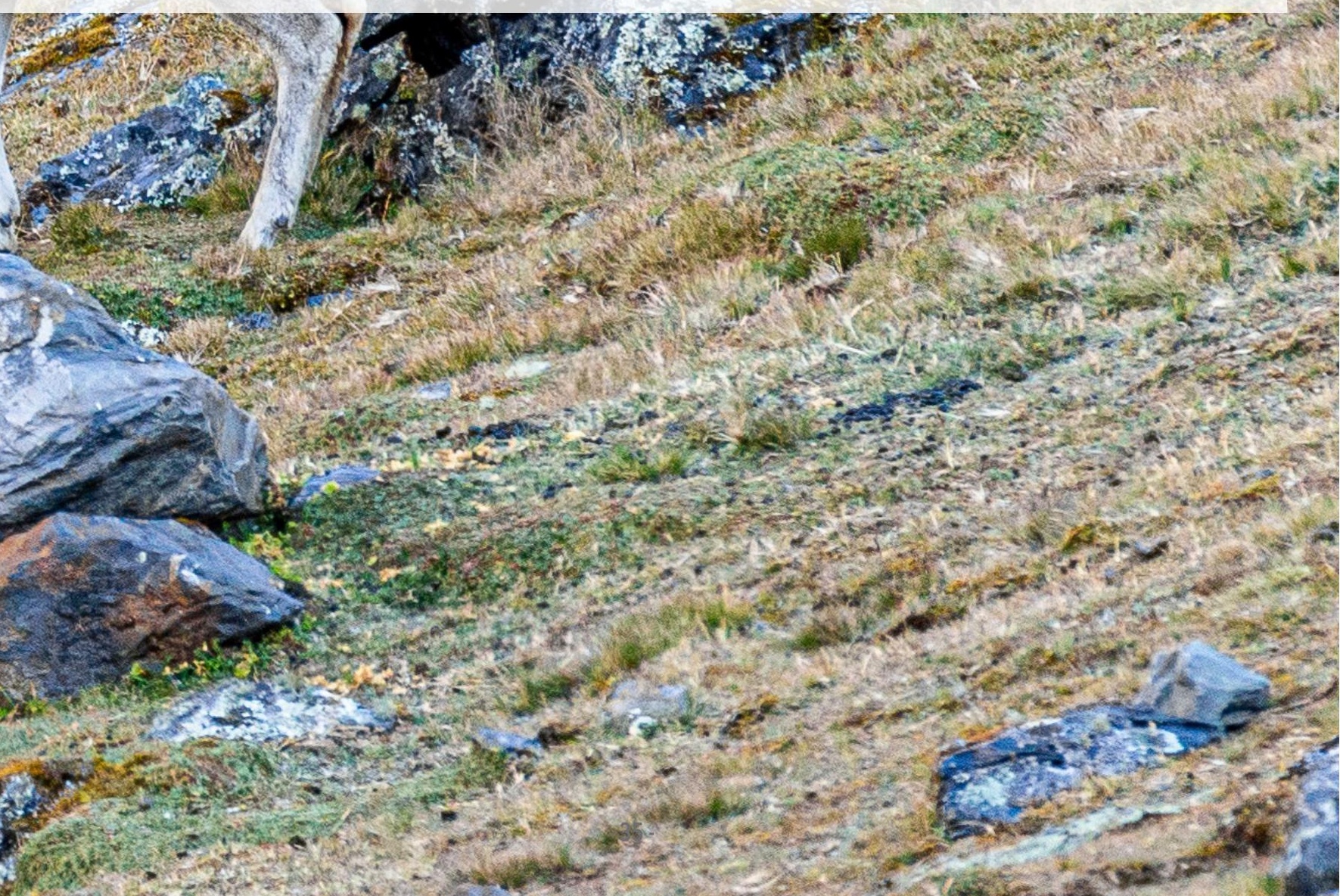




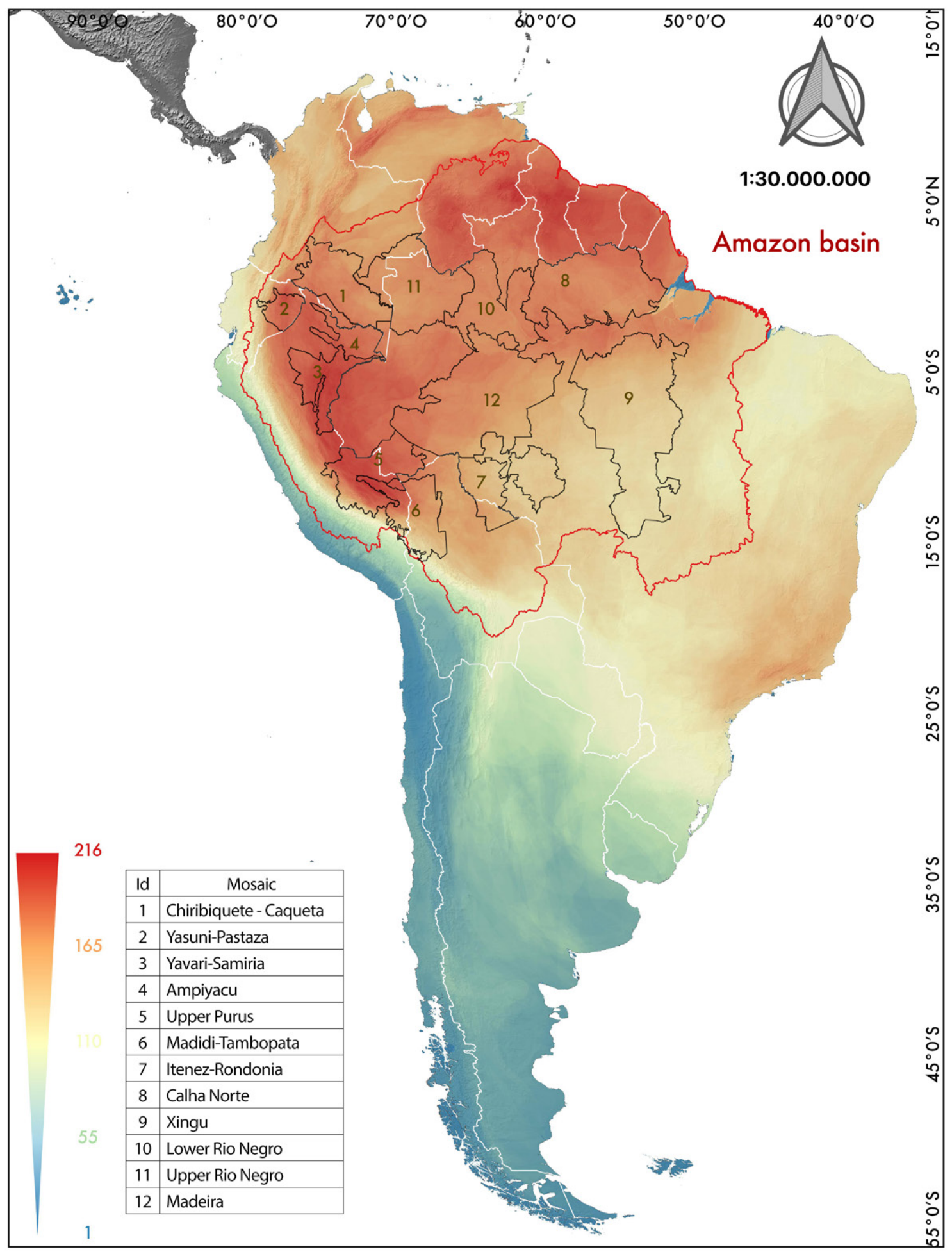

Figure 6: Mammal Species Richness per $\mathrm{km}^{2}$ in South America 

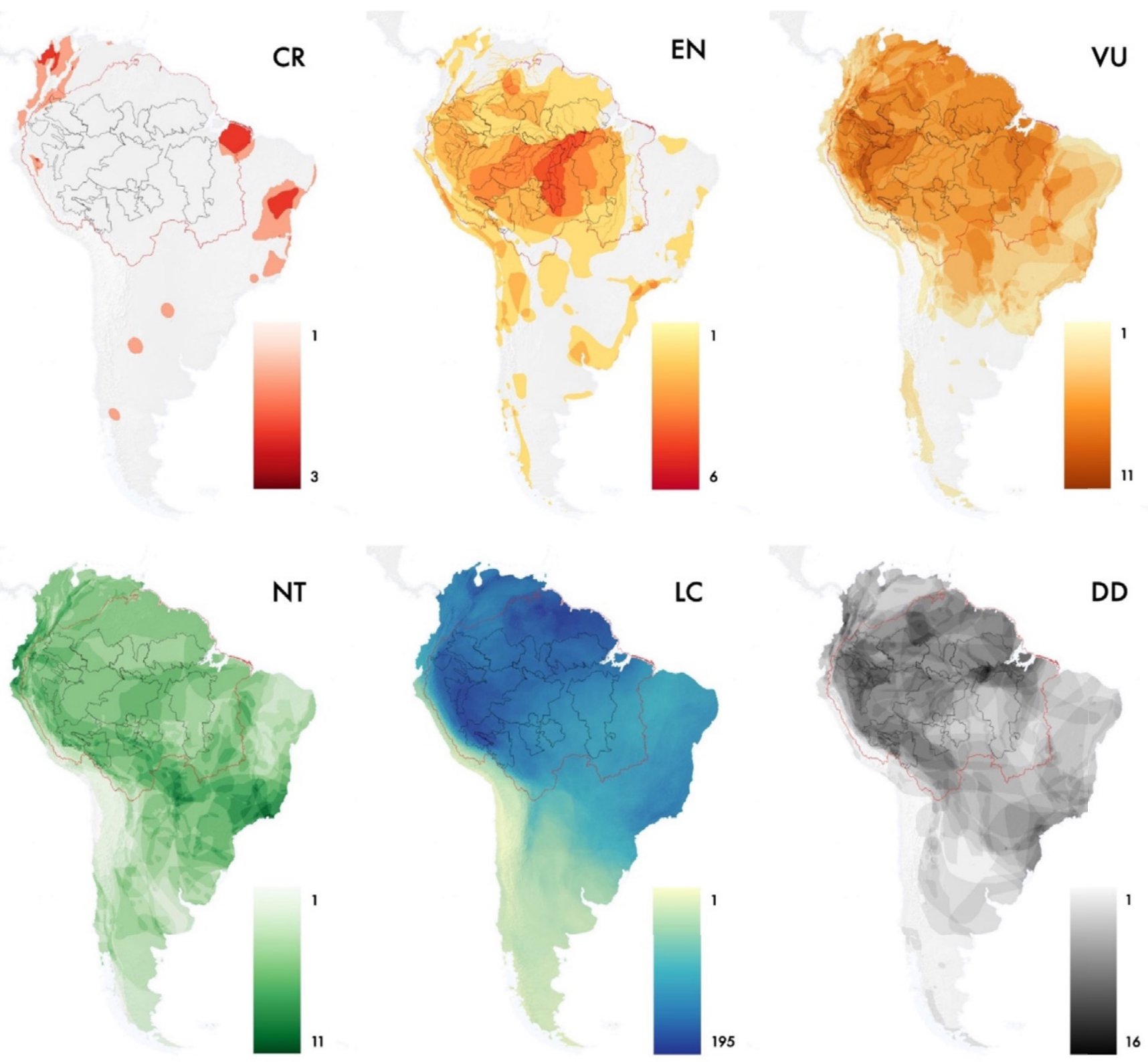

Figure 7: Threatened Mammal Species Richness per $\mathrm{km}^{2}$ in South America using IUCN (2018) Red Lists. Threatened Categories: Critically Endangered (CR); Endangered (EN); Vulnerable (VU); Near Threatened (NT); Least Concern (LC); Data Deficient(DD). 


\section{Rupicola peruviana}

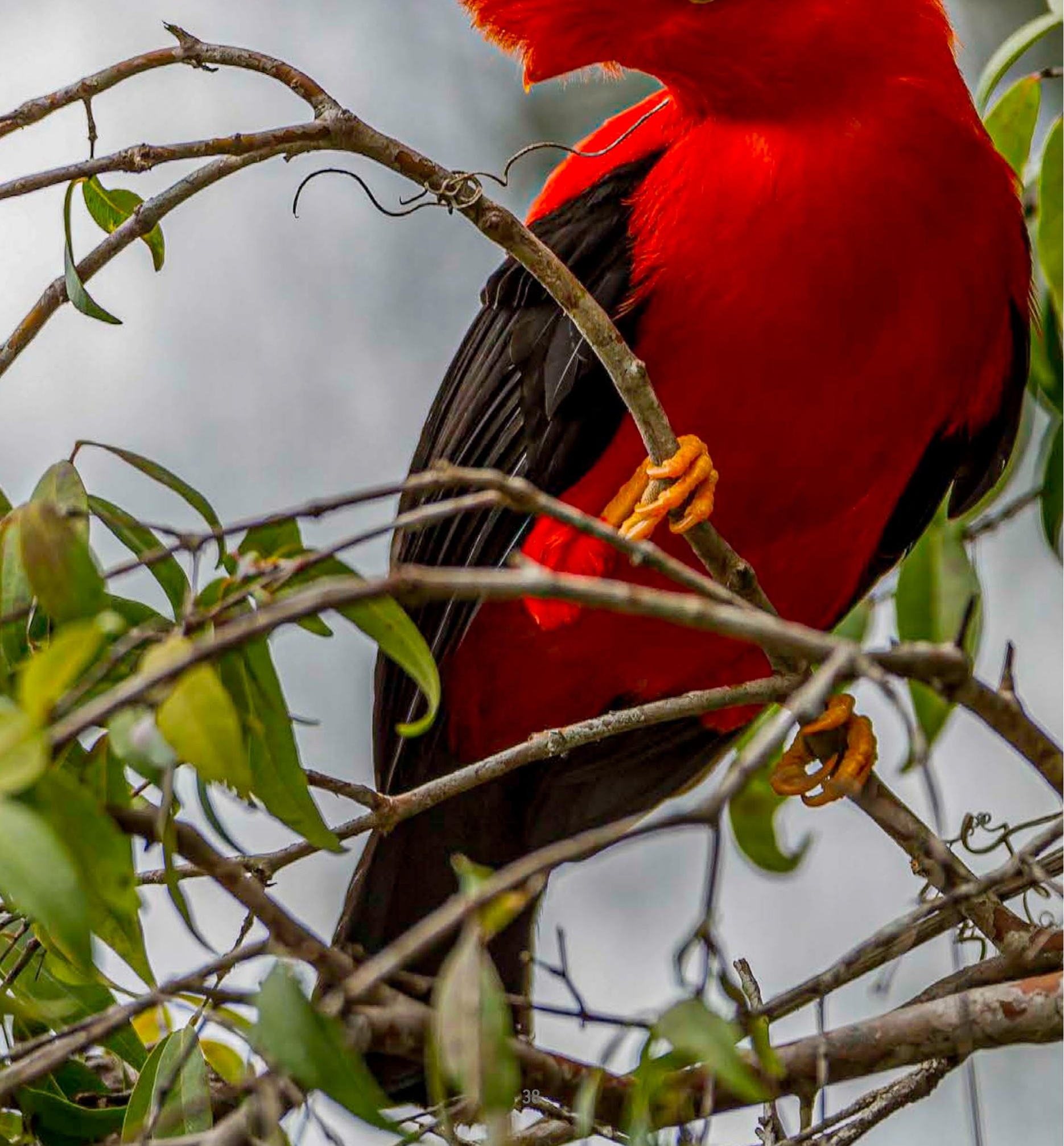




\section{b. Birds}

The majority of the areas with the greatest concentration of bird species in South America are found in the Amazon basin (Figure 6). Once again, the areas with the highest concentrations of up to 596 species per $\mathrm{km}^{2}$ are in the western Amazon, highlighting the importance of the Yasuni-Pastaza, Yavari-Samiria, Ampiyacu, Upper Purus conservation mosaics, and parts of Madidi-Tambopata, Madeira, Calha Norte and Xingu conservation mosaics.

The areas with the highest concentration of threatened bird species according to the lower threatened IUCN categories (NT, LC) in South America (Figure 9), are predominantly found in the Amazon, whereas Endangered and Vulnerable concentrations are predominantly concentrated outside the Amazon. In South America concentrations of Critically Endangered species reach 4 species per $\mathrm{km}^{2}$ and are found in eastern Brazil and small portions of Bolivia, Ecuador, Argentina, Perú y Chile, and within the Madidi-Tambopata conservation mosaic.

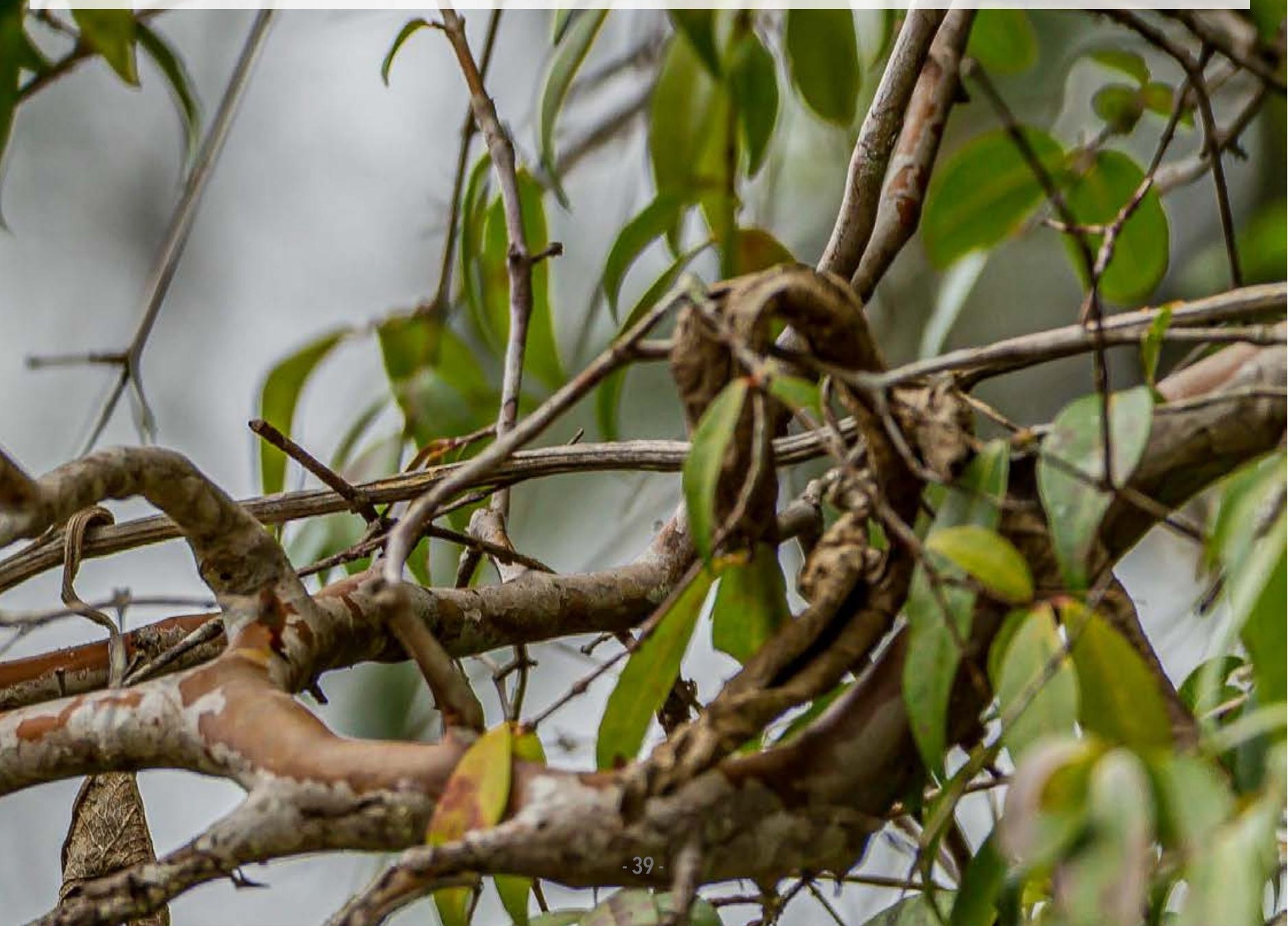




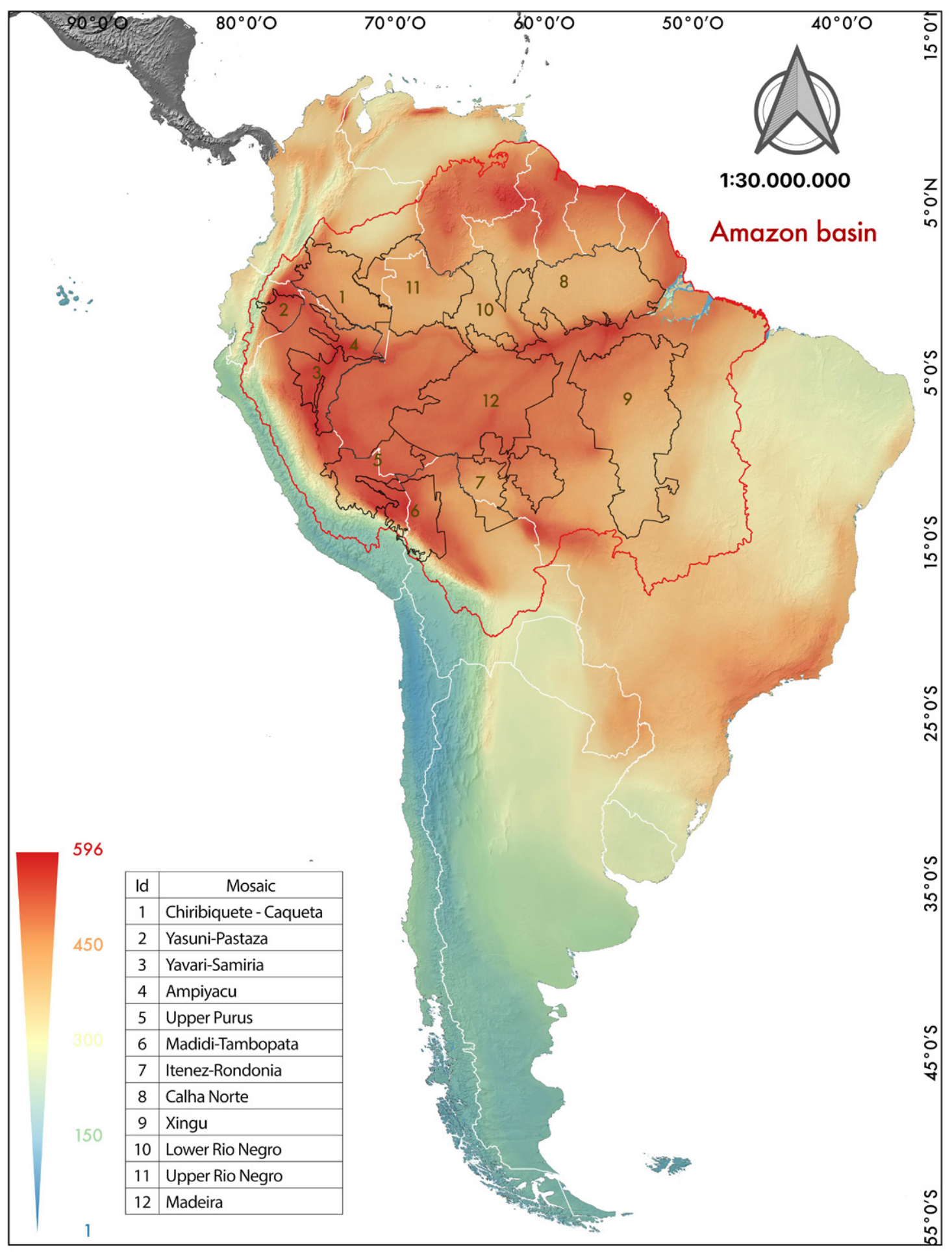

Figure 8: Bird Species Richness per $\mathrm{km}^{2}$ in South America 

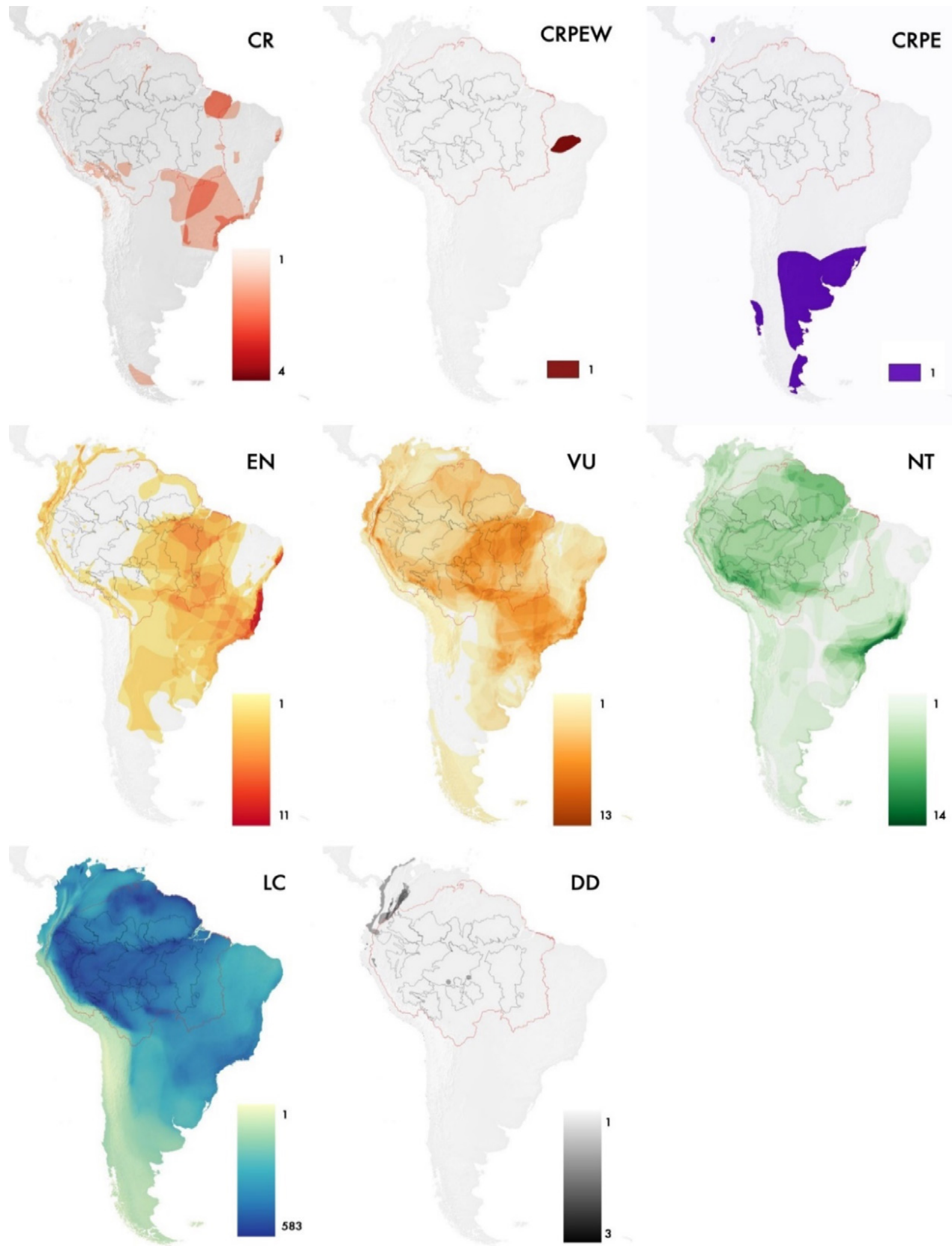

Figure 9: Threatened Bird Species Richness per km²in South America using IUCN (2018) Red Lists. Threatened Categories: Critically Endangered (CR); Critically Endangered \& Possibly Extinct in the Wild (CRPEW); Critically Endangered \& Possibly Extinct (CRPE); Endangered (EN); Vulnerable(VU); Near Threatened (NT); Least Concern (LC); Data Deficient(DD). 
Figure 10 compares the total number of species in the twelve conservation mosaics, the Amazon basin and South America, in each taxonomic group and in each IUCN category: Critically Endangered (CR), Endangered (EN), Vulnerable (VU), Near Threatened (NT), Least Concern (LC) and Data Deficient (DD), highlighting that in general the majority of species are considered Least Concern.

Amphibians have the highest number of species in the more threatened categories $(E N, C R)$ within the conservation mosaics supported by the Gordon and Betty Moore Foundation, and the Amazon basin and South America in general. Meanwhile, amphibians and mammals have the highest number of species classified as Data Deficient (Figure 10). 


\section{MOORE MOSAIC}

AMAZON BASIN

SOUTHAMERICA

Amphibians

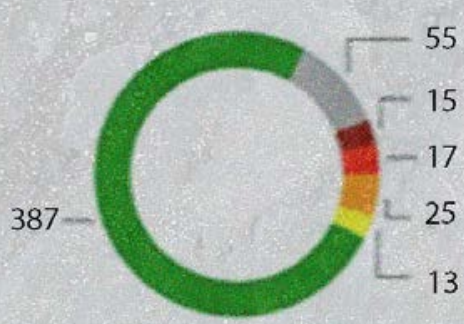

Reptiles
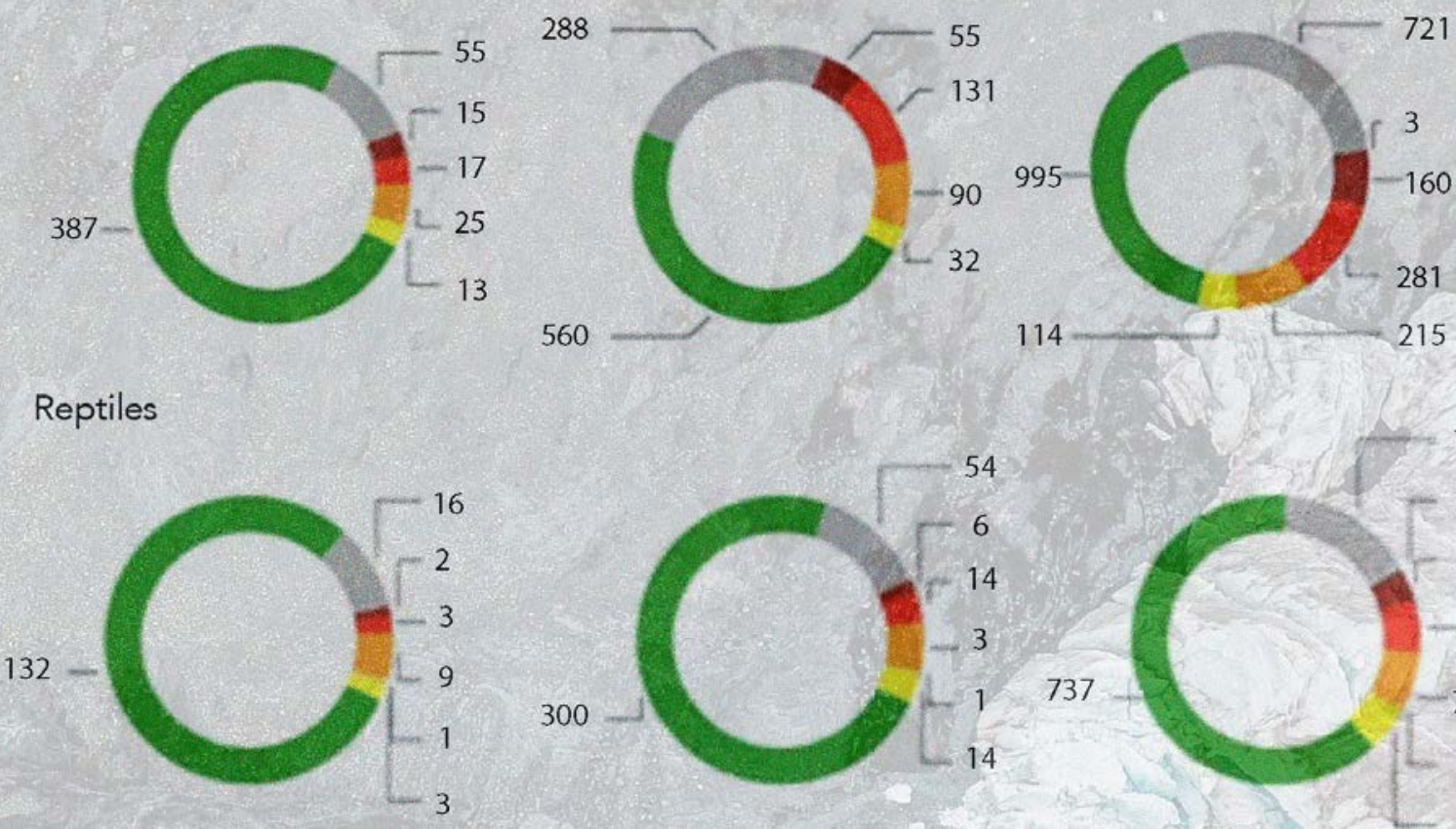

Birds
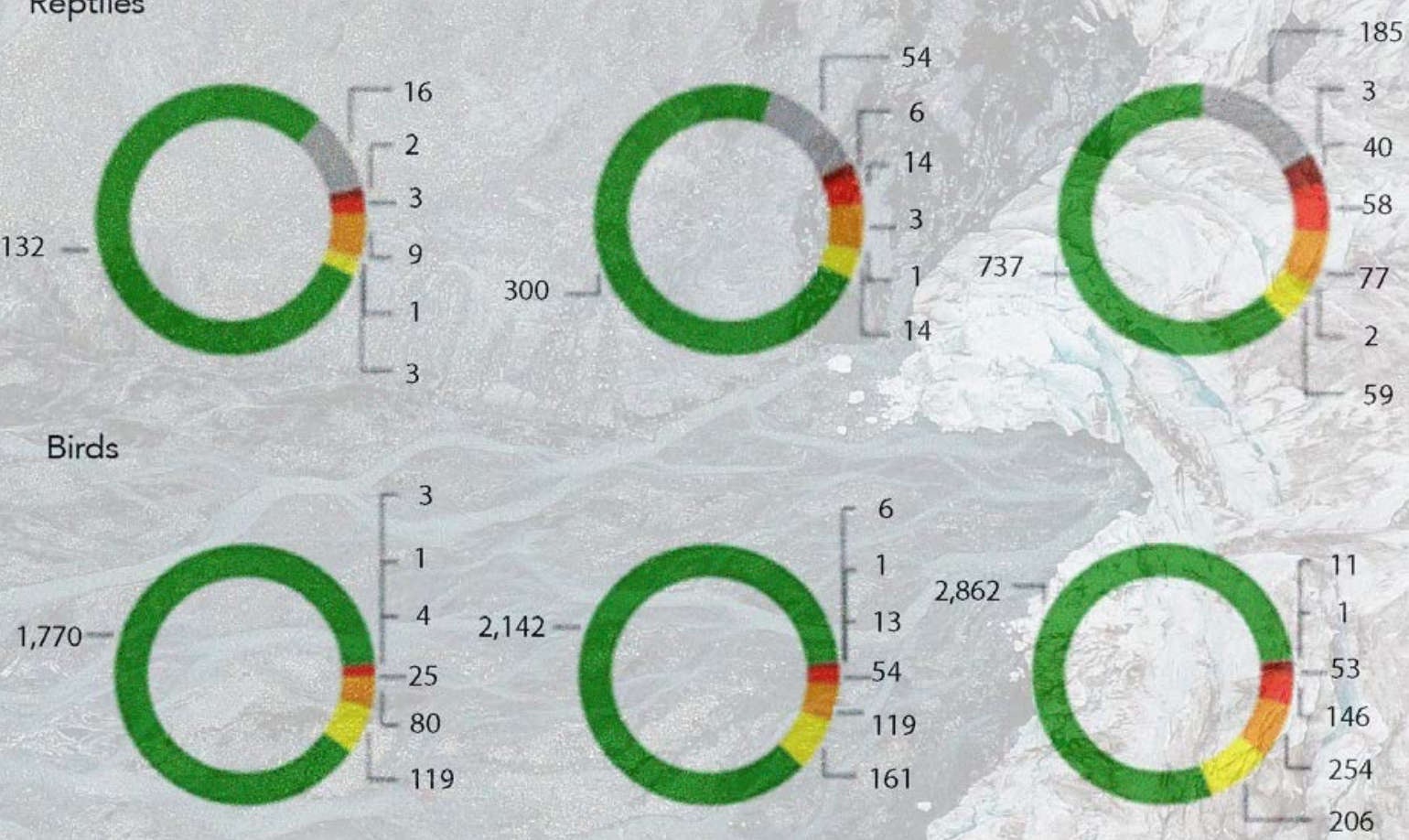

Mammals

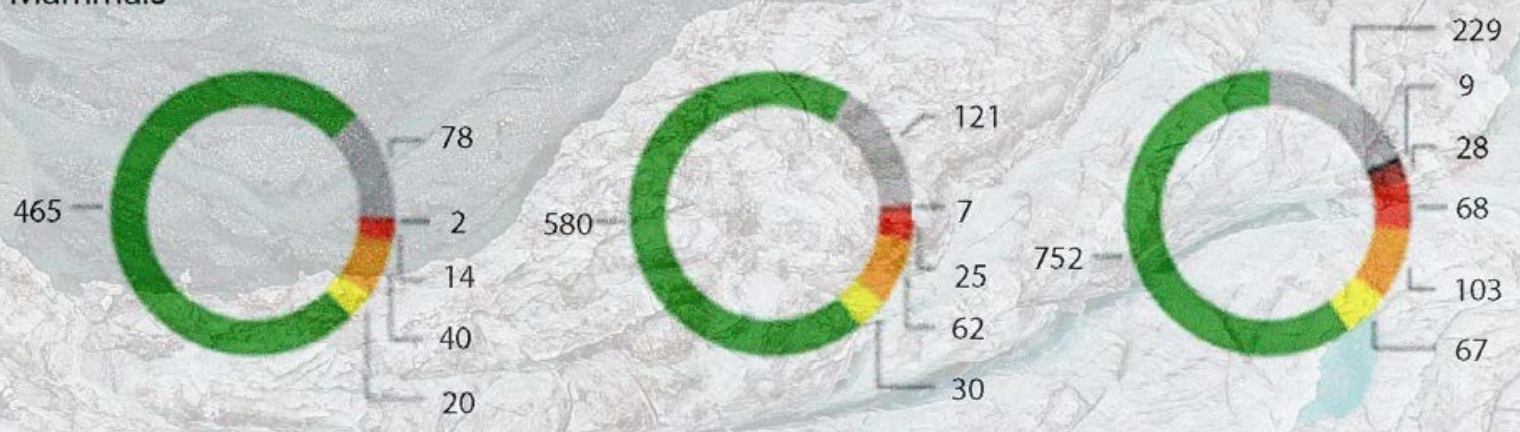

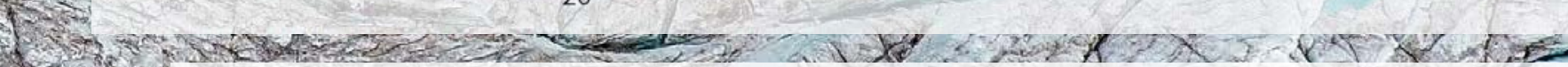
ragling $x \rightarrow 3$

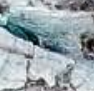

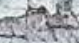

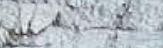

Figure 10. Number of Species in the GBMF Conservation Mosaics, Amazon Basin and South America according to IUCN Conservation Status:

Extinct; Extinct in the Wild; Critically Endangered; Endangered; Vulnerable; $\square$ At Risk/Conservation Dependent;

NearThreatened; Least Concern; - NotAssessed. 


\section{CONCLUSIONS}

In summary, from a biodiversity conservation perspective, the twelve conservation mosaics that the Gordon and Betty Moore Foundation has supported over the last 15 years are individually valuable, including some of the most biologically diverse places on Earth. Indeed, when analyzed collectively the conservation mosaics are making an extraordinary contribution towards the conservation of Amazonian, continental and global biodiversity. The twelve conservation mosaics cover 53.84\% of the Amazon basin and are expected to hold 3,836 species, representing $66.64 \%$ of Amazon species, $37.95 \%$ of South American species and $10.51 \%$ of species in the world. As expected these percentages are higher for mammals $(76.66 \%$ Amazon species, $48.38 \%$ South American species, $10.47 \%$ global species) and birds (80.02\% Amazon species, 55.5\% South American species, 18\% global species), which tend to have larger distributions than reptiles (56.8\% Amazon species, 26.65\% South American species, 5.33\% global species) and amphibians (42.89\% Amazon species, 19.82\% South American species, $7.22 \%$ global species).

Our study underlines the pressing need for further efforts to document biodiversity across the Amazon including the confirmation of these expected vertebrate lists in the conservation mosaics supported by the Gordon and Betty Moore Foundation. Recent efforts such as Identidad Madidi in Bolivia and Nuna in Ecuador are emphasizing the importance of communicating the extraordinary biological diversity of flagship conservation areas, as well as revealing the presence of significant numbers of undescribed vertebrate species at these globally outstanding locations.

Finally, it is important to emphasize that the number and size of the conservation mosaics supported by the Gordon and Betty Moore Foundation may not be ideal in terms of maximizing biodiversity conservation, as hundreds of smaller units across the Amazon basin would cover a larger percentage of Amazonian biodiversity. However, conservation efforts have many goals and objectives and from the perspective of consenving wider ranging species with greater individual area needs including iconic wildlife such as jaguars, white-lipped peccaries, scarlet macaws, Andean bears and giant otters, the conservation mosaic approach is an effective strategy. Similarly, this larger scale approach also contributes towards maintaining forest cover in the Amazon, promoting effective watershed management, as well as ensuring critical ecosystem function and services. 


\section{Mex}
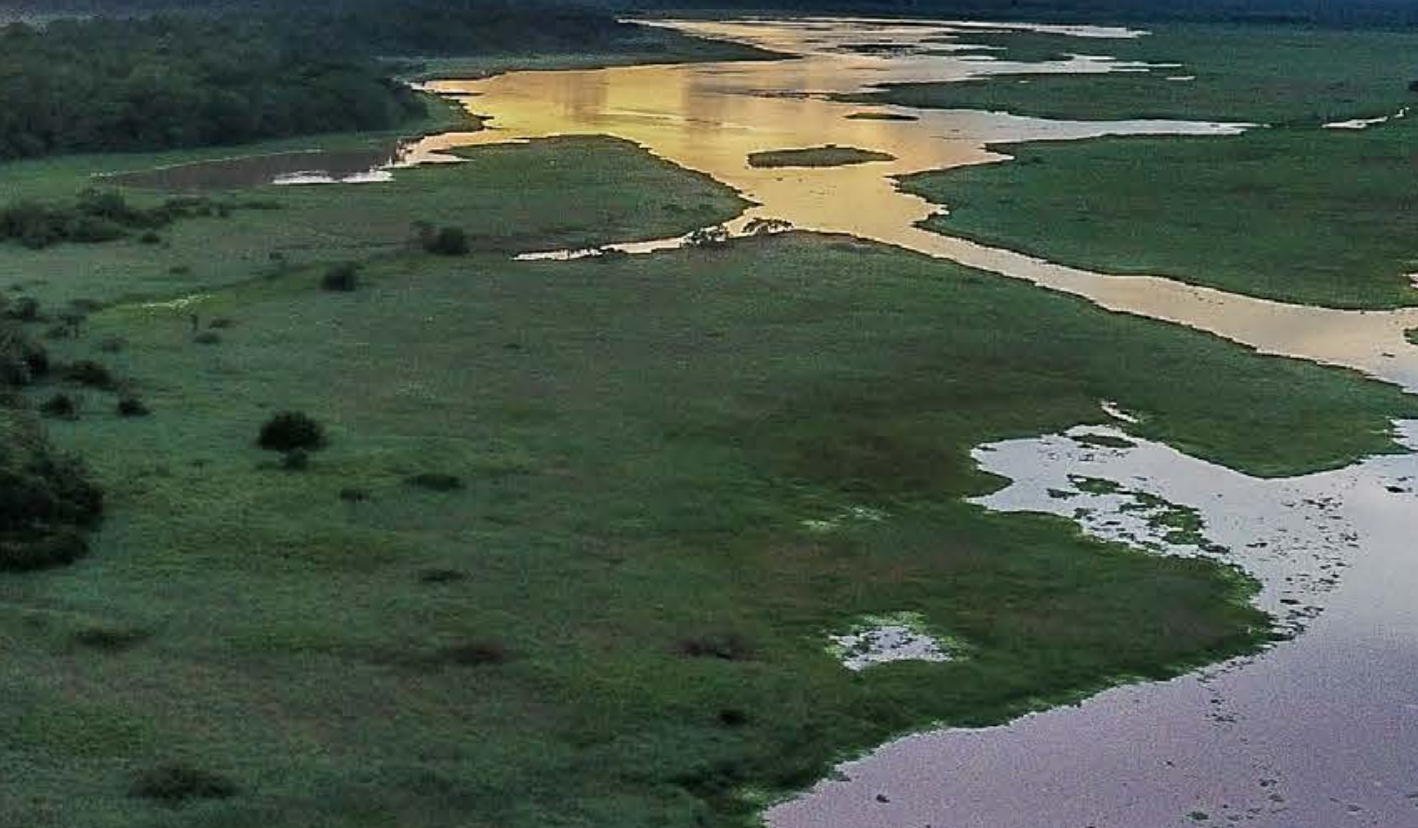

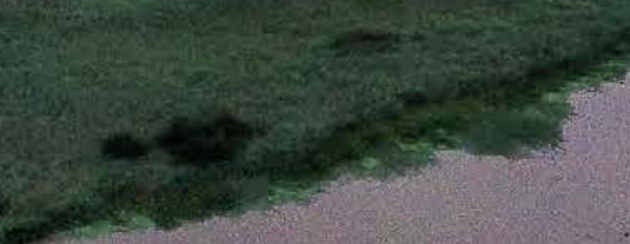
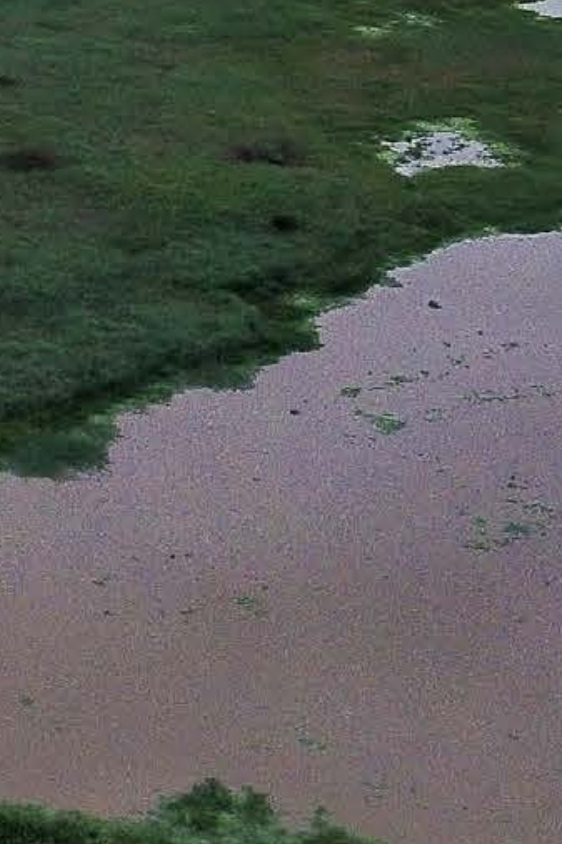

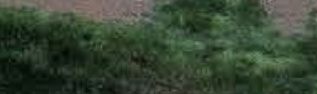




\section{REFERENCES}

- $\quad$ Aguirre LF, Tarifa T, Wallace R, Salazar-Bravo J, Bernal $\mathrm{NH}$, Siles L \& Aliaga-Rossel E. 2019. Lista actualizada y comentada de los mamíferos de Bolivia. Ecologia en Bolivia.

- AmphibiaWeb. 2019. <https://amphibiaweb.org> University of California, Berkeley, CA, USA. Accessed 21 March 2019.

- Barlow J, França F, TA Gardner, et al. 2018. The future of hyperdiverse tropical ecosystems. Nature 559: 517 526.

- BirdLife International \& NatureServe. 2018. Bird Species Distribution Maps of the World. BirdLife International, Cambridge, UK and NatureServe, Arlington, USA.

- $\quad$ Canale GR, Peres C, Guidorizzi CE, Ferreira-Gato CA \& Kierulff CM. 2012. Pervasive defaunation of forest remnants in a tropical biodiversity hotspot. Plos One 7: e41671.

- Castro G \& S Riega-Campos. 2014. An Analysis of International Conservation Funding in the Amazon. Washington DC Ecosystem Services. Palo Alto, CA: Gordon and Betty Moore Foundation. http://www.vale. $\mathrm{com} / \mathrm{brasil} / \mathrm{PT} / \mathrm{ab}$ outvale/news/Documents/AmazonConservationFunding-Analysis-Publication-2014.pdf $24 \mathrm{pp}$.

- Colwell RK. 2009. Biodiversity: concepts, patterns, and measurement. In: Levin S. (Eds.). The Princeton Guide to Ecology (pp. 257-263). Princeton, NJ: Princeton University Press.

- Conrad O, Bechtel B, Bock M, Dietrich H, Fischer E, Gerlitz L, Wehberg J, Wichmann V \& Böhner J. 2015. System for Automated Geoscientific Analyses (SAGA) v. 2.1.4, Geosci. Model Dev., 8, 1991-2007, doi:10.5194/ gmd-8-1991-2015.

- De Oliveira TG, Mazim FD, Vieiria 00, Barnett APA, Do N Silva G, Soares JBG, Santos JP, Da Silva VF, Araujo PA, Tchaika L \& Miranda CL. 2016. Nonvolant mammal megadiversity and conservation issues in a threatened Central Amazonian hotspot in Brazil. Tropical Conservation Science 2016: 1-16.

- $\quad$ Dirzo R \& Raven PH. 2003. Global state of biodiversity and loss. Annual Review Environment and Resources 28: $137-167$.

- Foley JA, Asner GP, Costa MH, Coe MT, DeFriest R, Gibbs
HK, Howard EA, Olson S, Patz J, Ramankutty N \& Snyder P. 2007. Amazonia revealed: forest degradation and loss of ecosystem goods and services in the Amazon Basin. Frontiers in Ecology and the Environment 5: 2532.

- Foley JA, DeFries R, Asner GP, Barford C, Bonan G, Carpenter SR, Chapin FS, Coe MT, Daily GC, Gibbs HK, et al. 2005. Global consequences of land use. Science 309: $570-574$.

- Frost DR. 2019. Amphibian Species of the World: an Online Reference. Version 6.0 (21 January, 2019). Electronic Database accessible at http://research.amnh. org/herpetology/amphibia/index.html. American Museum of Natural History, New York, USA.

- GADM database. 2018. GADM hosted at Center for Spatial Sciences at the University of California, Davis, version 3.4, April 2018.

- Gaston KJ \& Spicer JI. 2004. Biodiversity: An Introduction. Blackwell, USA. 207 pp.

- GBIF.org (14 August 2018). 2019. GBIF Occurrence Download https://doi.org/10.15468/dl.exampledonotcite. Accessed 20 May, 2019.

- Gregorius HR, Bergmann F \& Wehenkel C. 2003. Analysis of biodiversity across levels of biological organization: a problem of defining traits. Perspectives in Plant Ecology, Evolution and Systematics 5: 209-218.

- Gullison RE \& Harned J. 2018. Progress and challenges in consolidating the management of Amazonian protected areas and indigenous territories. Conservation Biology 0: 1-11

- Hoorn C, Wesselingh FP, ter Steege H, Bermudez MA, Mora A, Sevink J, Sanmartín I, Sanchez-Meseguer A, Anderson CL, Figueiredo JP, Jaramillo C, Riff D, Negri FR, Hooghiemstra H, Lundberg J, Stadler T, Särkinen T \& Antonelli A. 2010. Amazonia through time: Andean uplift, climate change, landscape evolution, and biodiversity. Science 330: 927-931.

- Horn CM, Vargas-Paredes VH, Gilmore MP \& Endress BA. 2018. Spatio-temporal patterns of Mauritia flexuosa fruit extraction in the Peruvian Amazon: Implications for conservation and sustainability. Applied Geography 97: 98-108.

- Hutter CR, Guayasamin JM \& Wiens JJ. 2013. Explaining Andean megadiversity: the evolutionary 
and ecological causes of glass frog elevational richness patterns. Ecol. Lett.16: 1135-1144.

- $\quad$ IUCN 2018. The IUCN Red List of Threatened Species. Version 2016-1. http://www.iucnredlist.org.

- ITIS. 2019. Retrieved [March, 1, 2019] from the Integrated Taxonomic Information System on-line database, http://www.itis.gov.

- Jenkins CN, Pimm SL\& Joppa LN. 2013. Global patterns of terrestrial vertebrate diversity and conservation. Proceedings of the National Academy of Sciences 110: E2602-10.

- Kolář F, Dušková E. \& Sklenář P. 2016. Niche shifts and range expansions along cordilleras drove diversification in a high-elevation endemic plant genus in the tropical Andes. Mol. Ecol. 25: 4593-4610.

- Laurance WF, Sayer J \& Gassmam KE. 2014. Agricultural expansion and its impacts on tropical nature. Trends Ecology and Evolution 29: 107-116.

- Latrubesse EM, Arima EY, Dunne T, Park E, Baker VR, d'Horta FM, Wight C, Wittmann F, Zuanon J, Baker PA, Ribas CC, Norgaard RB, Filizola N, Ansar A, Flybjerg B \& Stevaux JC. 2017. Damming the rivers of the Amazon basin. Nature 546: 363-369.

- $\quad$ Lim BK. 2018. Review of mammalogical research in the Guianas of northern South America. Integrative Zoology 11: 151-161.

- Mammal Diversity Database. 2019. www. mammaldiversity.org. American Society of Mammalogists. Accessed 10 March, 2019.

- $\quad$ Minteer CR, Smith MC, Lake LC \& Pokorny E. 2018. Teaching complex ecological concepts through a demonstration garden: biodiversity, invasive species, and conservation in practice. The American Biology Teacher 80: 346-352.

- MorenoCE.2001. Métodos para medirla biodiversidad. M\&T-Manuales y Tesis SEA, vol.1.Zaragoza, España. 84 $\mathrm{pp}$.

- Moreno $C E$, Barragán F, Pineda E \& Pavón NP. 2011. Reanalyzing alpha diversity: alternatives to understand and compare information about ecological communities. Revista Mexicana de Biodiversidad 82: 1249-1261.

- $\quad$ Myers N, Mittermeier RA, Mittermeier CG, da Fonseca GAB \& Kent J. 2000. Biodiversity hotspots for conservation priorities. Nature 403: 853-858.

- Paglia AP, Fonseca GAB da, Rylands AB, Herrmann $G$, Aguiar LMS, Chiarello AG, Leite YLR, Costa LP, Siciliano S, Kierulff MCM, Mendes SL, Tavares VdaC, Mittermeier RA \& Patton JL. 2012. Lista Anotada dos Mamíferos do Brasil / Annotated Checklist of Brazilian Mammals, $2^{\mathrm{a}}$ Edição / 2nd Edition. Occasional Papers in Conservation Biology 6: 1-76.

- $\quad$ Patton JL, Pardiñas UFJ \& Guillermo D'Elía (Eds). 2015. Mammals of South America, Volume 2: Rodents. University of Chicago Press, USA. 1384 pp.

- $\quad$ Peres C. 1990. Effects of hunting on western Amazonian primate communities. Biological Conservation 54: 4759.

- Peres C. 2007. Basin-wide effects of game harvest on vertebrate population densities in Amazonian forests: implications for animal-mediated seed dispersal. Biotropica 39: 304-315.

- Programa de las Naciones Unidas para el Medio Ambiente (PNUMA). 2010. Perspectivas del Medio Ambiente: América Latina y el Caribe. GEO ALC 3. 80 pp.

- Prüssmann J, Suárez CF \& Chaves ME. 2017. Atlas of Conservation Opportunities in the Amazon Biome under Climate Change Considerations. WWF, Redparques, FAO, UICN Y PNUMA, Cali, Colombia. 80 pp.

- Purvis A, Newbold T, De Palma A, Contu S, Hill SLL, Sanchez-Ortiz K, et al. 2018. Modelling and projecting the response of local terrestrial biodiversity worldwide to land use and related pressures: the PREDICTS project. Advances Ecology in Research 58: 201-241.

- $\quad$ OGIS Development Team. 2018. QGIS Geographic Information System. Open Source Geospatial Foundation Project. https://qgis.org.

- $\quad$ Quan Q, Che X, Wu Y, Wu Y, Zhang Q, Zhang M \& Zou F. 2017. Effectiveness of protected areas for vertebrates based on taxonomic and phylogenetic diversity. Conservation Biology 32: 355-365.

- RAISG, 2016. Cartografía Histórica de Áreas Naturales Protegidas y Territorios Indígenas en la Amazonía. Version digital. 161 pp.

- Ramírez-Chaves HE, Suárez-Castro AF \& GonzálezMaya JF. 2016. Cambios recientes a la lista de los mamíferos de Colombia. Mammalogy Notes | 
Notas Mastozoológicas Sociedad Colombiana de Mastozoología 3: 1-20.

- Remsen JV Jr, Areta JI, Cadena CD, Claramunt S, Jaramillo A, Pacheco JF, Robbins MB, Stiles FG, Stotz DF \& Zimmer KJ. Version [20-12-2018]. 2018. A classification of the bird species of South America. American Ornithologists' Union. http://www. museum. Isu.edu/ Remsen/SACCBaseline.htm.

- Roll U, Feldman A, Novosolov M, Allison A, Bauer A, Bernard R, et al. 2017. The global distribution of tetrapods reveals a need for targeted reptile conservation. Nat. Ecol. Evol. 1: 1677-1682.

- $\quad$ Ron SR, Merino-Viteri A \& Ortiz DA. 2019. Fauna del Ecuador. Version 2019.0. Museo de Zoología, Pontificia Universidad Católica del Ecuador. <https://bioweb. bio/faunaweb/amphibiaweb>, fecha de acceso 3 de enero, 2019.

- $\quad$ Rowe R \& Myers M (Eds.). 2019. All the World's Primates, www.alltheworldsprimates.org. Primate Conservation Inc., Charlestown Rl. Accessed 21 April, 2019.

- Sánchez JH. \& L. Daniel. 2012. Lista actualizada y comentada de los mamíferos de Venezuela. Memoria de la Fundación La Salle de Ciencias Naturales 2012 ("2010") 1: 173-238.

- Sloan S, Jenkins CN, Joppa LN, Gaveau DLA \& Laurence WF. 2014. Remaining natural vegetation in the global biodiversity hotspots. Biological Conservation 177: 1224.

- Sobral M, Silvius KM, Overman H, Oliveira LFB, Raab TK \& Fragoso JMV. 2017. Mammal diversity influences the carbon cycle through trophic interactions in the Amazon. Nat. Ecol. Evol. 1: 1670-1676.

- Socolar JB, Gilroy JJ, Kunin WE \& Edwards DP. 2015. How should beta-diversity inform biodiversity conservation? Trends in Ecology \& Evolution 31: 67-80.

- Strelneck D \& Vilela T.2017. International Conservation Funding in the Amazon: an updated analysis. Informe Técnico, Gordon and Betty Moore Foundation, Palo Alto, California, USA.

- Teta P, Abba AM, Cassini GH, Flores DA, Galliari CA, Lucero SO \& Ramírez M. 2018. Lista revisada de los mamíferos de Argentina. Mastozoología Neotropical, Mendoza, Versión on-line 1: 1-37.

- Tilman D, Balzer C, Hill J \& Befort BL. 2011. Global food demand and the sustainable intensification of agriculture. Proceedings of the National Academy of Sciences of the United States of America 108: 20260 20264.

- Tirira DG. 2018. Mamíferos del Ecuador: lista actualizada de especies Mammals of Ecuador: updated checklist species Diego G. Tirira (versión 2018.1) http://mamiferosdelecuador.com

- Uetz P, Freed P \& Hošek J. 2019. The Reptile Database, http://www.reptile-database.org. Accessed 15 Feb, 2019.

- Valencia R, Balslev H, Paz G \& Miño C. 1994. High tree alpha-diversity in Amazonian Ecuador. Biodiversity and Conservation 3: 21-28.

- Venticinque E, Forsberg B, Barthem RB, Petry P, Hass L, etal. 2016. An explicit GIS-based river basin framework for aquatic ecosystem conservation in the Amazon. Earth Syst. Sci. Data 8: 651-661/ SNAPP Western Amazon Group - Amazon Aquatic Ecosystem Spatial Framework.

- Venticinque E, Forsberg B, Barthem RB, Petry P, Hass $\mathrm{L}$, et al. 2018. SNAPP Western Amazon Group-Amazon Aquatic Ecosystem Spatial Framework. Knowledge Network for Biocomplexity. doi:10.5063/F1BG2KX8.

- Vieria RRS, Ribeiro BR, Resende FM, Brum FT, Machado N, Sales LP, Macedo L, Soares-Filho B \& Loyola R. 2018. Compliance to Brazil's forest code will not protect biodiversity and ecosystem services. Diversity Distribution 24: 434-438.

- Wolters V, Bengtsson J \& Zaitsev AS. 2006. Relationship among the species richness of different taxa. Ecology 87: 1886-1895. 




\section{Appendix}

Criteria for Estimated Species Distribution Polygons according to the IUCN, regarding Species Presence, Origin and Temporality

\begin{tabular}{|c|c|c|}
\hline \multicolumn{3}{|r|}{ PRESENCE } \\
\hline CODE & PRESENCE & DEFINITION \\
\hline 1 & Present & $\begin{array}{l}\text { The species is known to occur in the area with records in the last } 20-30 \text { years and remaining suitable and viable habitat at } \\
\text { appropriate altitudes. Present range is included within EOO calculations, as well as historical distribution of the species. }\end{array}$ \\
\hline 2 & Probably Present & $\begin{array}{l}\text { The species is considered probable based on extrapolations, records or inference in suitable and viable habitat at appropriate } \\
\text { altitudes close to locations where the species is known to occur, either between known locations or an extension of a known area. } \\
\text { This code value has been discontinued due to ambiguity, but will be gradually eliminated. }\end{array}$ \\
\hline 3 & Possibly Present & $\begin{array}{l}\text { No record of the species in the area, but possibly present based on the distribution of adequate habitat and appropriate } \\
\text { altitudes, although the area is beyond known and probable distribution. The probability of occurrence is low, for example, } \\
\text { because it is beyond a geographic barrier, or because the area represents a significant range extension. Identifying possibly } \\
\text { present areas is useful to highlight areas that require further study. Possibly present areas are usually not included in EOO } \\
\text { calculations or in actual/historical distribution maps. }\end{array}$ \\
\hline 4 & Possibly Extinct & $\begin{array}{l}\text { The species was known to occur in recent history (post } 1500 \mathrm{AD} \text { ), but is very probably extinct due to habitat loss or other threats, } \\
\text { with no confirmed recent records despite research efforts. Possibly extinct areas are not included in EOO calculations, but are } \\
\text { included in historical distribution maps. }\end{array}$ \\
\hline 5 & Extinct & $\begin{array}{l}\text { The species was known to occur in recent history (post } 1500 \mathrm{AD} \text { ), but has been confirmed as no longer present in the area, as } \\
\text { it has not been registered in recent exhaustive efforts. Extinct areas are not included in EOO calculations, but are included in } \\
\text { historical maps. }\end{array}$ \\
\hline 6 & Presence Uncertain & $\begin{array}{l}\text { A record for the species exists for the area, but requires verification or is questionable due to identification uncertainty or } \\
\text { authenticity, or the precision of the location. Uncertain presence areas are not included in EOO calculations or in actual/historical } \\
\text { maps. }\end{array}$ \\
\hline \multicolumn{3}{|r|}{ ORIGIN } \\
\hline CODE & ORIGIN & DEFINITION \\
\hline 1 & Native & The species is or was native to the area. \\
\hline 2 & Reintroduced & The species was reintroduced through direct or indirect human activities. \\
\hline 3 & Introduced & The species was introduced outside of its historical distribution through direct or indirect human activities. \\
\hline 4 & Errant & The species is registered sporadically, but is known not to be native to the area. \\
\hline 5 & Uncertain Origen & Unknown origin of the species in the area. Could be native, introduced or reintroduced. \\
\hline 6 & Assisted Colonization & Species subject to intentional movement and liberation outside the native range to reduce extinction risk of the taxon. \\
\hline
\end{tabular}

\begin{tabular}{|c|c|l|}
\hline CODE & TEMPORALITY \\
\hline 1 & Resident & \multicolumn{1}{c|}{ DEFINITION } \\
\hline 2 & The species is considered as present year round. \\
\hline 3 & Reproductive season & The species is considered to occur regularly during the reproductive season and reproduces in the area. \\
\hline 4 & Non-reproductive season & The species is considered to occur regularly during the non-reproductive season. \\
\hline 5 & Migration areas & $\begin{array}{l}\text { The species is considered to occur regularly for brief periods during the year and during migrations between reproductive and } \\
\text { non-reproductive sites. }\end{array}$ \\
\hline & $\begin{array}{c}\text { Uncertain seasonal } \\
\text { occurrence }\end{array}$ & The species has been recorded in the area, but it is unknown whether resident or temporary visitor. \\
\hline
\end{tabular}





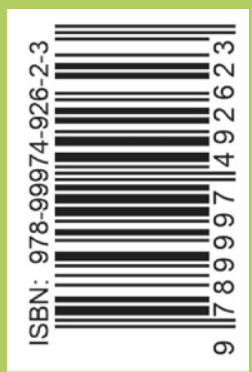

